\title{
THE ROLE OF HUMAN CAPITAL AND INSTITUTIONAL PERFORMANCE IN ACHIEVING COMPETITIVENESS AT SUHAR UNIVERSITY IN THE SULTANATE OF OMAN
}
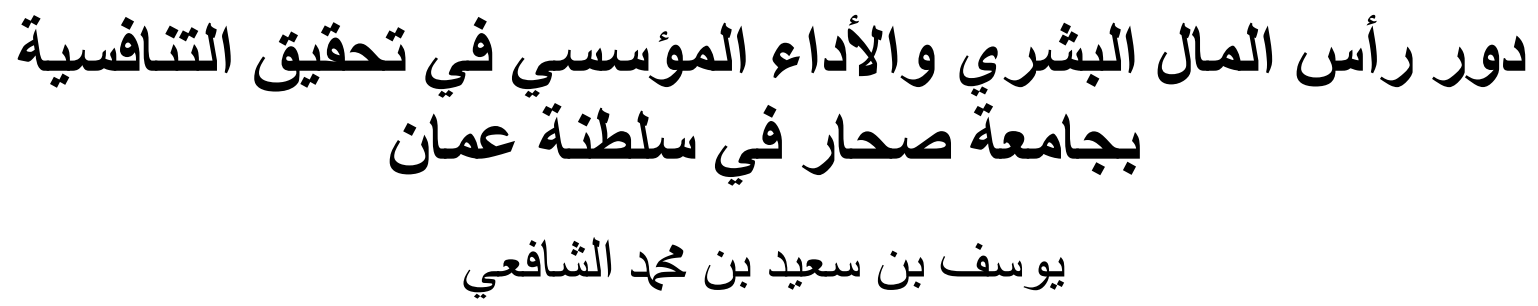
Yousuf Said Mohammed Al Shafii ${ }^{1 *}$, Mohamad Johdi Salleh², and Adnan Abd Rashid $^{3}$

${ }^{1}$ Ph.D. Candidate at the Faculty of Education, International Islamic University Malaysia (IIUM): yousufalshafey@hotmail.com/yousuf@voltampoman.com

${ }^{2}$ Prof. Dr. at the Kulliyyah of Education, International Islamic University Malaysia (IIUM); johdi@iium.edu.my

${ }^{3}$ Prof. Dr. at the Kulliyyah of Education, International Islamic University Malaysia (IIUM); adnan@iium.edu.my

${ }^{*}$ Corresponding author

\begin{abstract}
This quantitative study discussed the role of human capital and institutional performance in achieving competitiveness at Sohar University. The problem emerged that the university suffers from a weak system of research and development, in a climate that does not support creativity and innovation; What made it lose to many human cadres with experience, competence and qualifications, due to the university's lack of interest in the human component, which negatively affected institutional performance, and the university lost its competitive advantage. Therefore, the study aimed to diagnose the reality of human capital and institutional performance at Sohar University and their role in achieving competitiveness. The study includes the descriptive analytical method, and the questionnaire used contains (95) phrases distributed in three axes for the data collection. The study population consisted of (526) academics and administrators working at the university. A random sample was chosen according to the schedule of Grace and Morgan (1970) based on (222) academic and administratives. The findings revealed that: the level of human capital and institutional performance at Sohar University was (average), and the level of competitive performance was (high), and this indicates that the university possesses traditional methods in human resources management, despite its endeavor to apply global best practices, to achieve A distinguished position that makes it competitive in the labor market. The results also showed; The high level of human capital competencies at the University of Sohar, and the commitment of workers to expected behaviors, and a high level of awareness. Also, there is a statistically significant effect of the human capital variable on achieving competitiveness through the institutional performance of workers at Sohar University in the Sultanate of Oman.
\end{abstract}

Keywords: human resources, institutional performance, competitive advantage. 


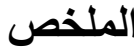

ناقثت هذه الدر اسة الكمية دور رأس المال البشري و الأداء المؤسسي في تحقيق التنافسية بجامعة صحار . برزت

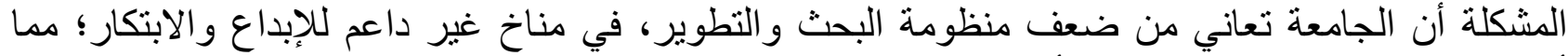

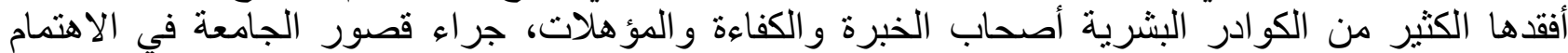

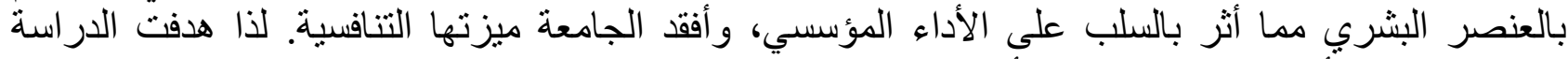

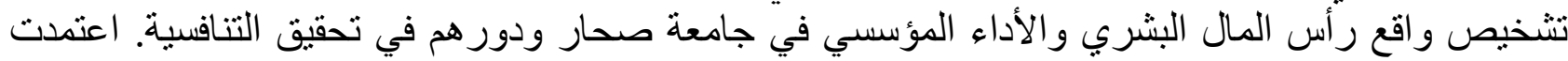

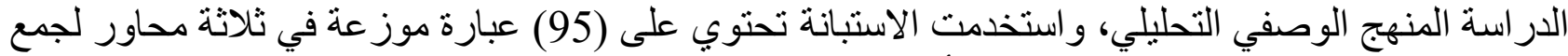

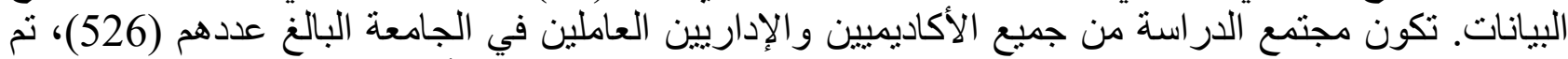

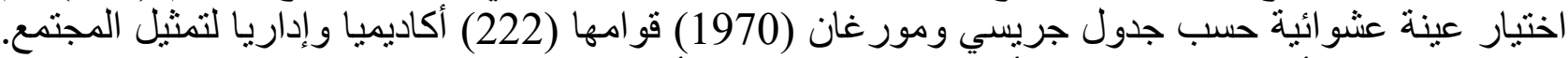

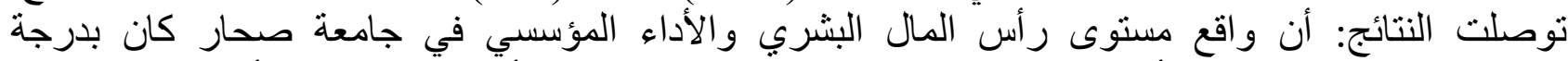

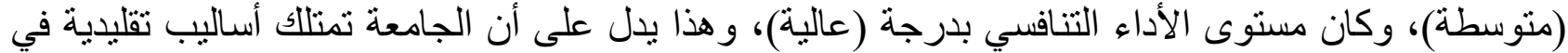

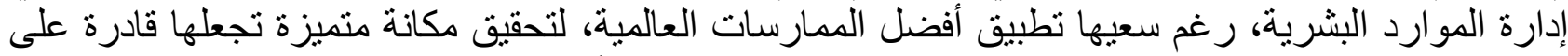

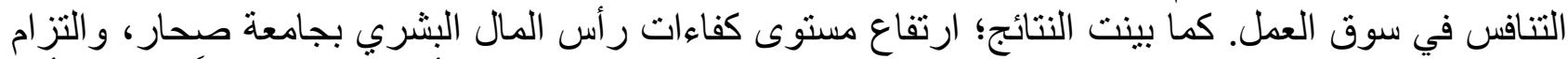

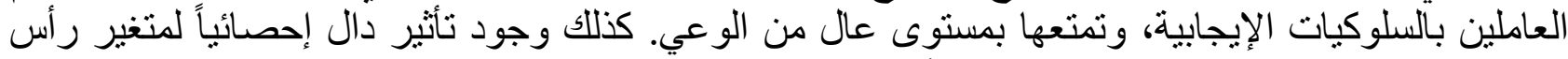

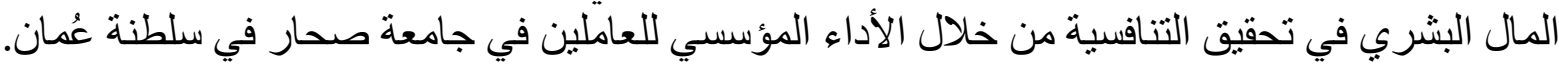

الكلمات المفتاحية: الموارد البشرية، الأداء المؤسسي، الميزة التنافسية.

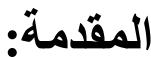

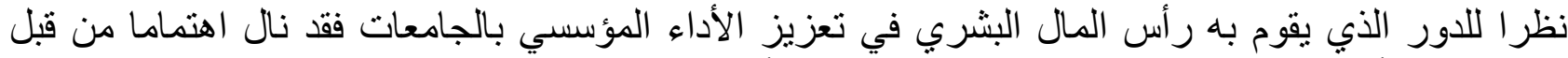

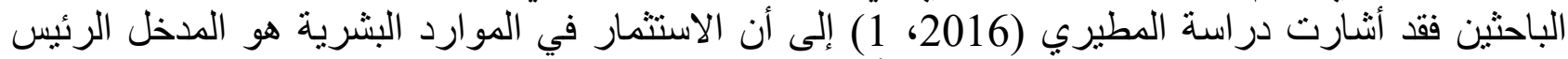

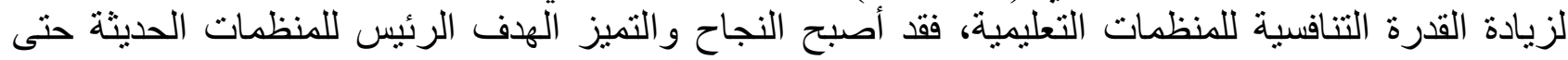

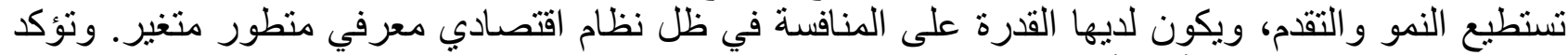

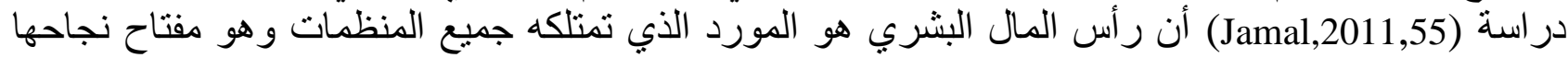

و استمر اريتها.

لذلك يعد رأس المال البشـري مـن أكبر المساهمين في الأداء المؤسسي الذي يشمل أداء كافة عناصر المنظومة

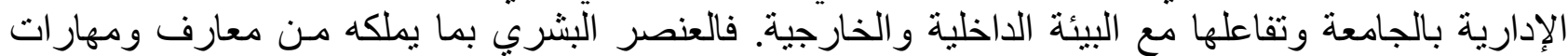

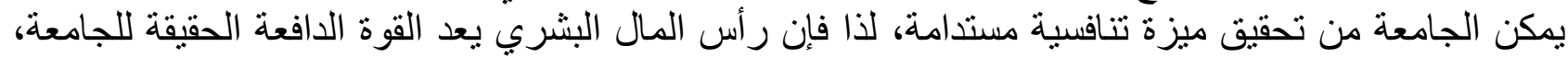

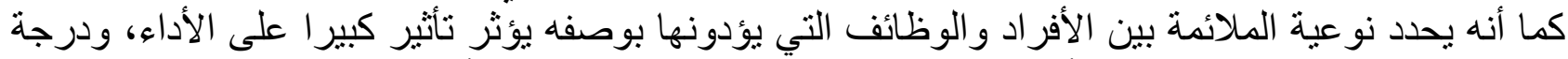
الرضا الوظيفي وكافة المتغير ات الأخرى ذات العلاقة بإدارة الموارد البرد البشرية (أبو بكر، 2011). يتكون رأس المال البشري من مجموعة المهار ات و المعارف و القدرات و الإمكانيات الكامنة لدى الأفراد و التي

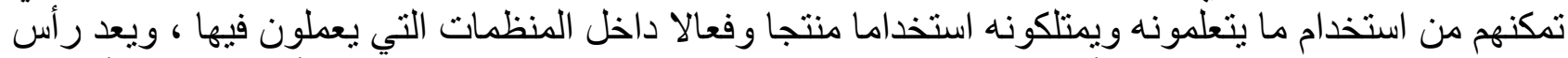

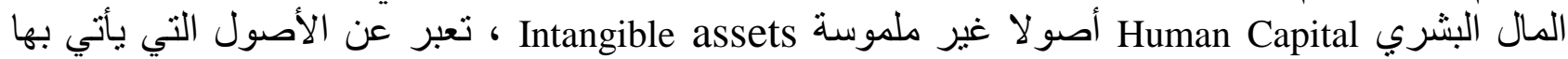

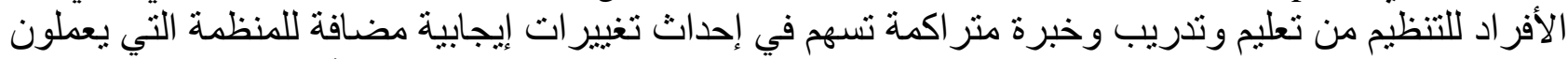

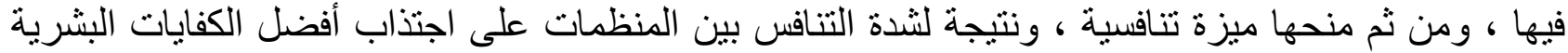
أصبح يشار إلى الجهود في هذا المجال " بالحروب من أجل الحصول على فئ رأس المال البشري" (المطيري

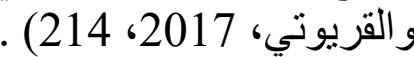

وحيث أن الجامعات في سلطنة عمان تعد الركيزة الأساسية للتعليم العالي، وتساهم في بناء الإنسان معرفياً وثقافياً

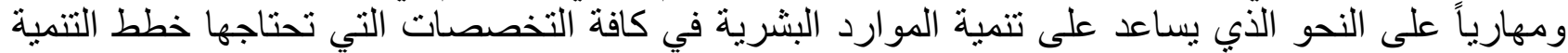

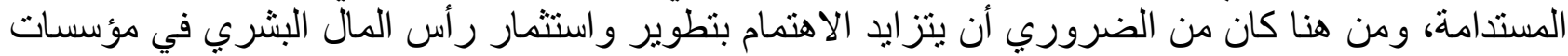
التعليم العالي وذلك بهدف تحسين مستوى جودة الأداء و تفعيل دور ها في قيادة التئ عمليات التنمية الثاملة. 
وتأكيداً على ذلك فقد أثـار (دريدي ، 2015، 146) إلى أن الموارد البشرية تمثل الركيزة الأساسية التي تعتمد

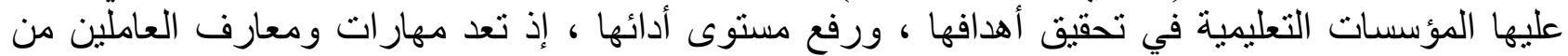

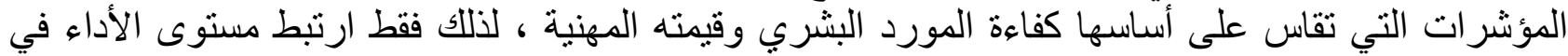

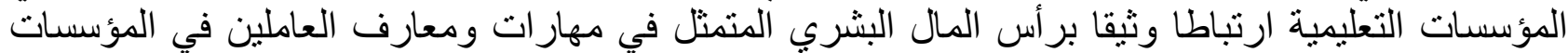

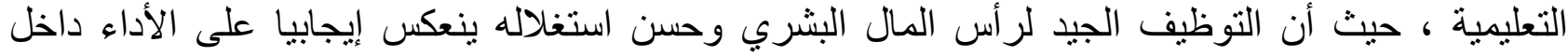

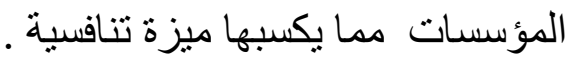

وقد ذكر (Tabiu,2013) إن رأس المال البشري يعد أكبر المساهمين في الأداء المؤسسي الذي يشمل أداء كافة

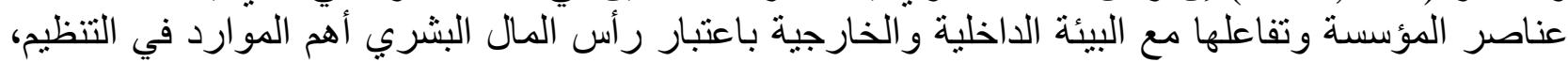

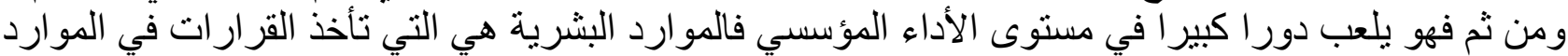

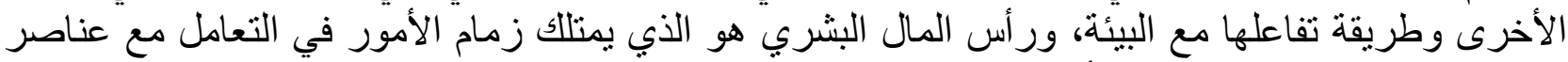

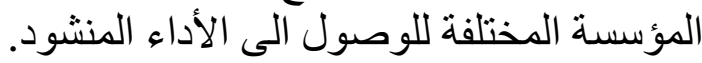

و أكدت در اسة (Marimuthu,2009) أن القدرة التنافسية في المنظمات تتطلب القدرة على الابتكار و الإبداع، و هذا

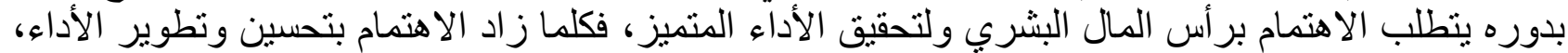

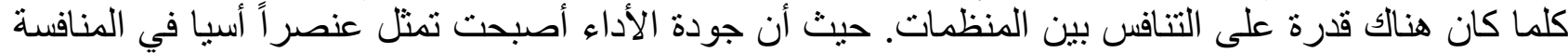

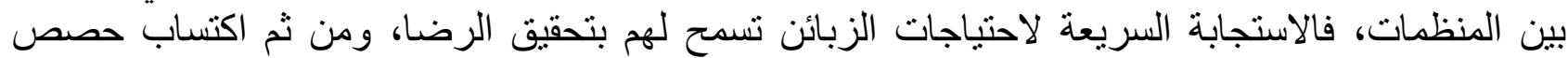

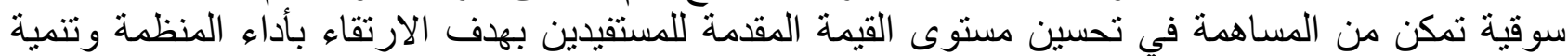

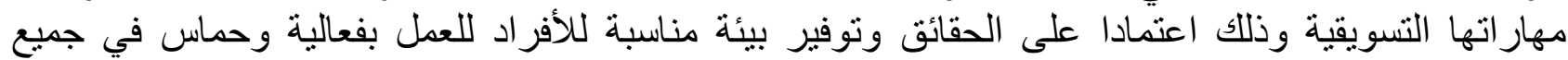
مجالات العمل (مصطفى، 2000).

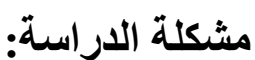

أكدت نتائج دراسة رشاد وحباكة (2017) أن الاهتمام برأس المال البشري بتم من خلال الاهتمام بالتعليم

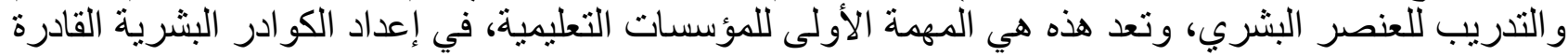

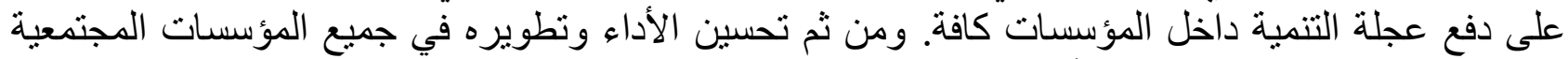

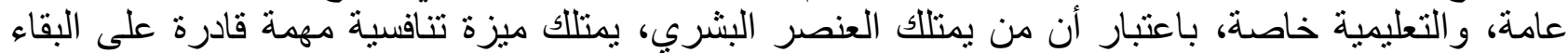

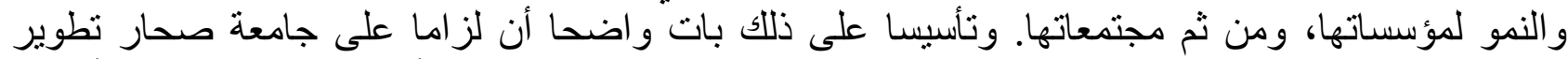

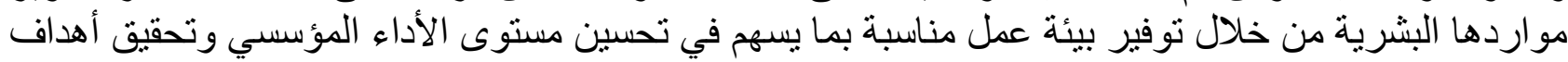
الجامعة لإكسابها مبزة تنافسية.

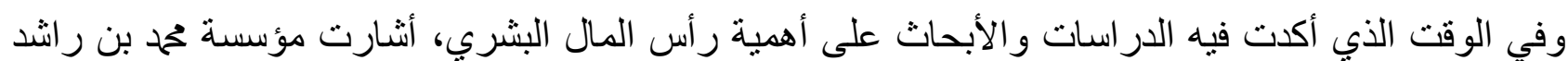

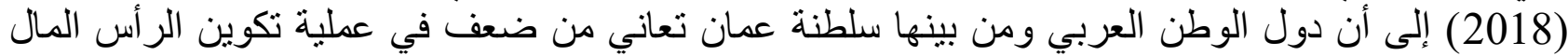
البشري مما جعل دول المنطقة تعاني من فقر الكوادر البشرية المدربة على الاستفادة من تكنولوجيا لونيا الاتصال

ولما كانت جامعة صحار أحد أهم مؤسسات التعليم العالي الخاص في سلطنة عمان ، كونها أول جامعة خاصة

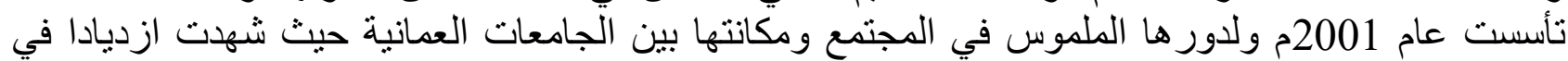

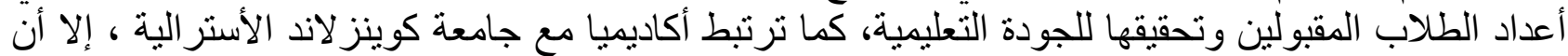
العديد من الدر اسات كدر اسة (القاسمية والعمرية،

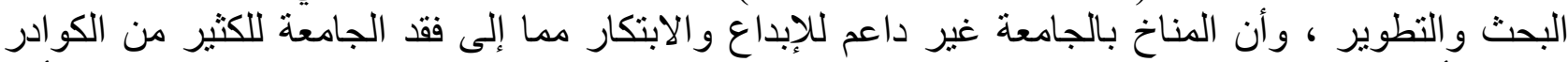

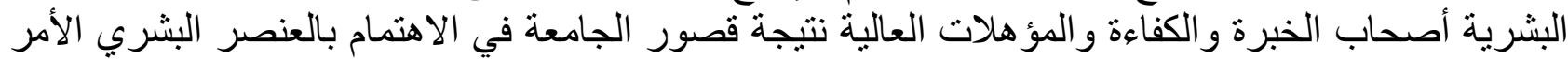
الذي أدى إلى جمود التطور و إلى وجود عنصر بشري يفتقر لمقومات الإبداع و التميز مما أثر بالسلب على التى الألى الأداء

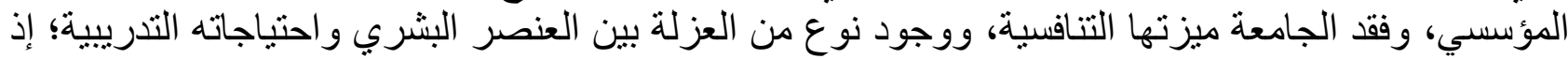
يعمل كل منهما بشكل مستقل عن الآخر. كذلك أوصت در اسة (بخيت ، 2010) بضرورة تنمية الموارد البشرية في جامعة صحار من خلال استقطاب 
و احتفاظ الجامعة بكو ادر بشرية قادرة على دفع عجلة التنمية البشرية، بالإضافة لما لديها من موارد بشرية على الى العي رأس العمل ممن يعول عليهم النهوض بالعمل ، وتحقيق أهداف العملية التعليمية أهداف الأراسة : 1. التعرف على مستويات رأس المال البشري والأداء المؤسسي و التنافس في جامعة صحار . . 2. التعرف على مؤ هلات رأس المال البشري بجامعة صحار .

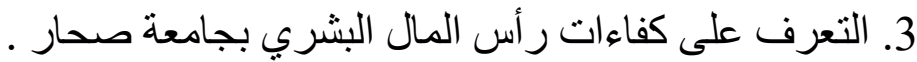
الار اسات السابقة:

فايزة بوراس (2018) "الاستثمار في رأس المال البشري كمدخل لاكتساب الميزة التنافسية المستدامة في

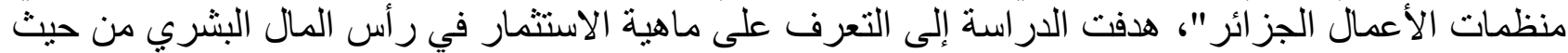

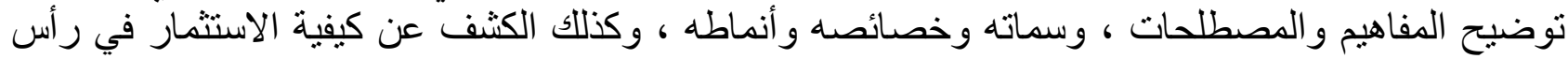

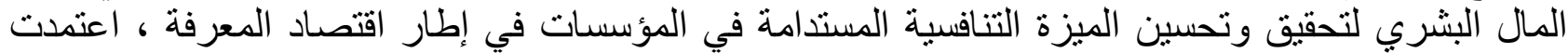

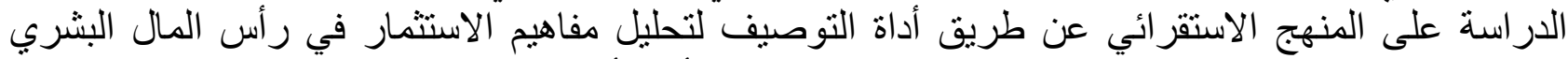

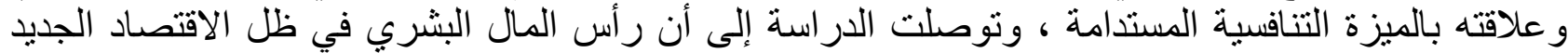

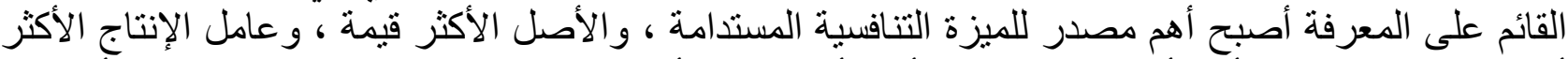
أهمية كما توصلت إلى أن رأس المال البشري أكثر أهمية من رأس المال المالي وباقي عناصر الإنتاج الأخرى . فادية إبراهيم تحمد شهاب وخليفه مصطفى أبو عاشور (2017) "إدارة الموارد البشرية في الجامعات الخاصة

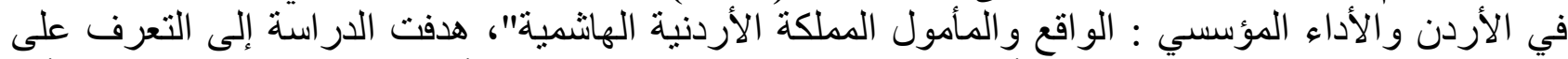

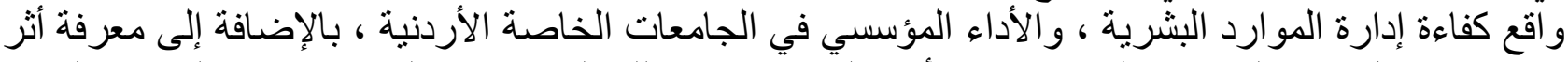

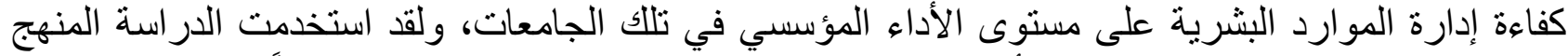

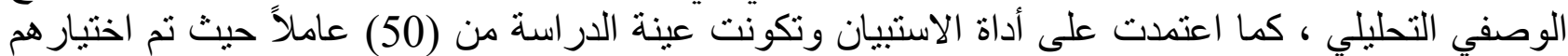

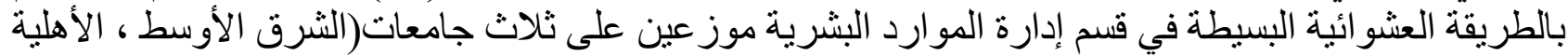

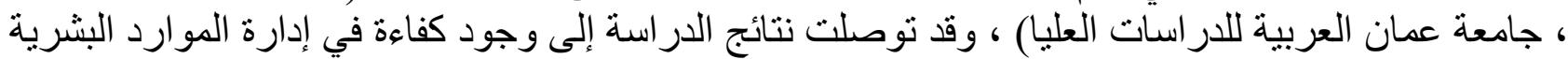

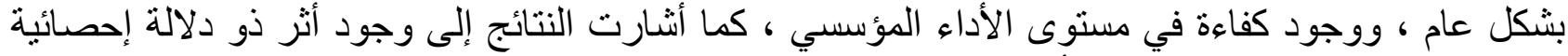

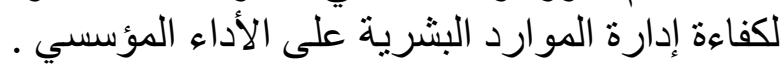
أجرى (Souleh , 2014) در اسة بعنوان "أثز إدارة رأس المال البشري على الابتكار في مر اكز البحوث العلمية

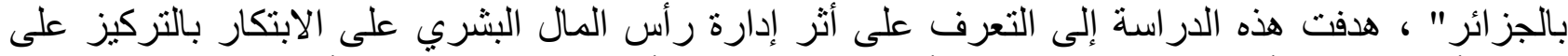

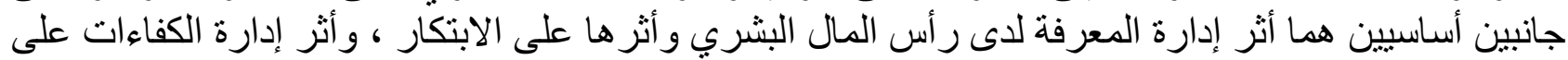

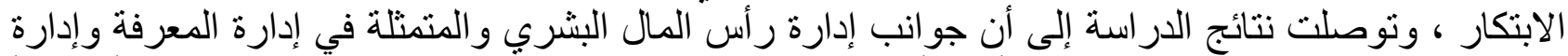

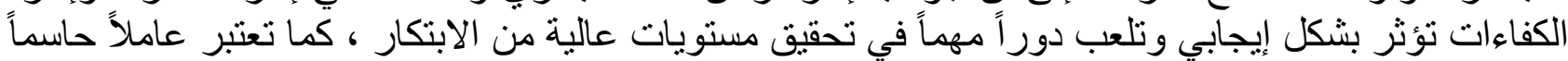

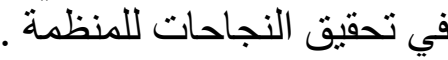

دراسة (Long-Sheng Lin,et.al , 2012) بعنوان "الكثف عن رأس المال البشري والأداء التنظيمي-الآثار المعتدلة لقوة المعرفة والحجم التنظيمي"، ورهدف إلى إلى التعرف على التى التأثير الإيجابي للكثنف عن رأس المال

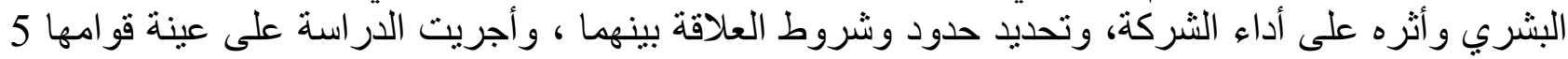

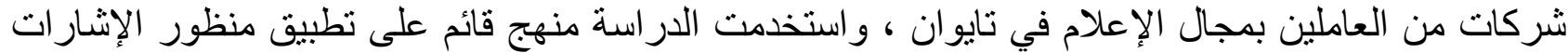

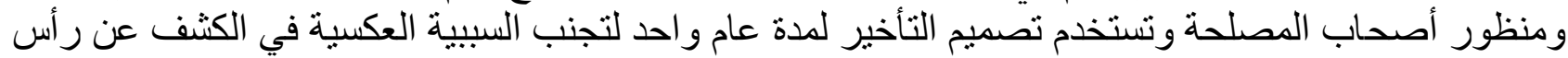

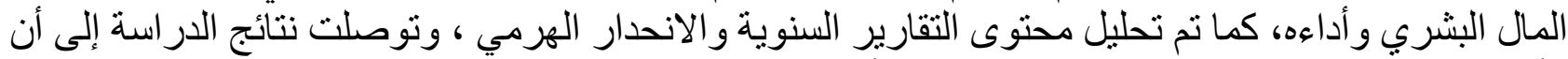

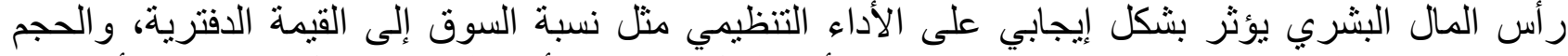
التنظيمي يفسد العلاقة بين الإفصاح عن عن معلومات رأس المال البشري وأدئ أداء الثركة بشكل سلبي، كما أن كثافة المعرفة لها تأثير معتدل إيجابي بين العلاقة سالفة الذكر. 
منهج الاراسة:

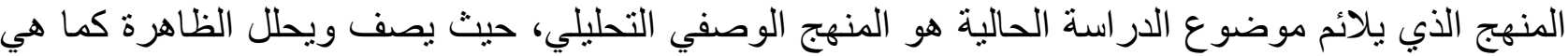

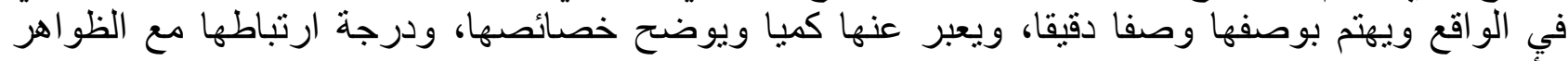
الأخرى.

\section{مجتمع الاراسة وعينتها:}

تكون مجتمع الدراسة الحالية من جميع الأكاديميين و الإداريين العاملين في جامعة صحار البالغ عددهم (526)

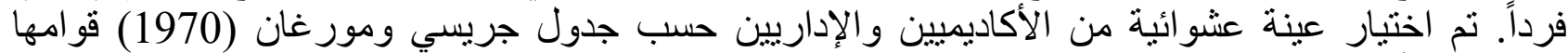
(222) فرداً لتمثيل مجتمع الدر اسة.

$$
\text { أدوات الاراسة: }
$$

صمم الباحث استبانة تحتوي على (95) عبارة موزعة في ثلاثة محاور هي: الأول مستويات ر أس المال البشري

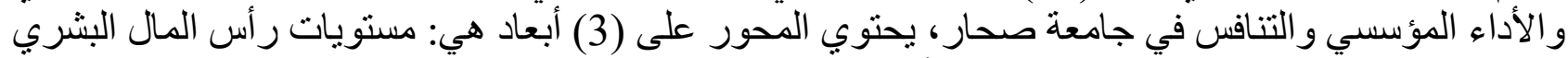
في الجامعة وفيه (11) عبارة، و مستويات الأداء المؤسسي في الجامعة صحار وتحته (19) عبارة، ومستويات

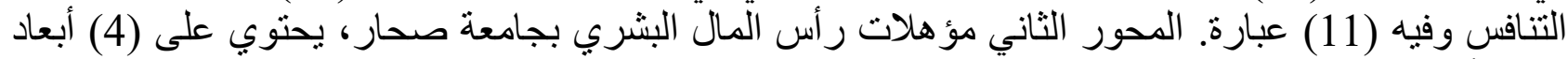

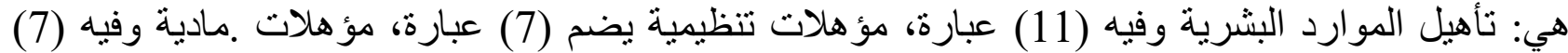

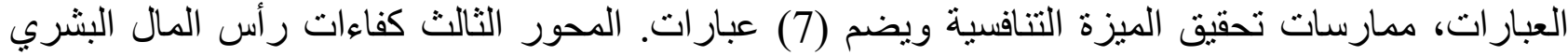

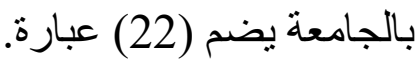

صدق الاستبانة:

\section{مؤشر صدق التكوين (الاتساق الاخلي):}

بعد عرض الاستبانة على مجمو عة من المحكمين المتخصصين، و الأخذ بملاحظاتهم، تم حساب صدق الداخلي

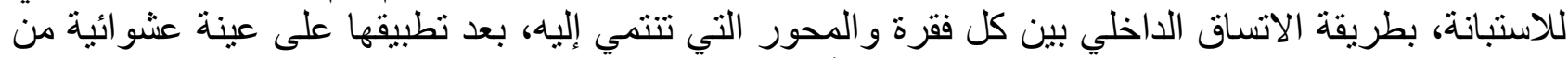

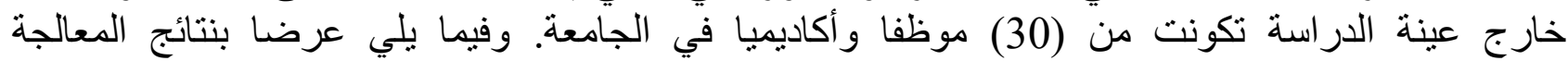
الإحصائية:

$$
\text { جدول (1) الاتساق الداخلي لققر ات محاور الأداة }
$$

\begin{tabular}{|c|c|c|c|}
\hline 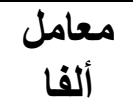 & 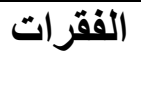 & فقرات المحاور & $ت$ \\
\hline 0.83 & 41 & في جامعة صحات رأس المال البشري والأداء المؤسسي والتنافس & 1 \\
\hline 0.978 & 32 & مؤ هلات ر أس المال البشري بجامعة صحار & 2 \\
\hline 0.992 & 22 & كفاءات رأس المال البشري بالجامعة & 3 \\
\hline 0.993 & 95 & ل معدل فقرات المحاور & \\
\hline
\end{tabular}

يوضح الجدول (1) أن قيم معاملات الارتباط بين جميع الفقرات و المحور الذي تنتمي إليه ذات قيم جيدة، كما

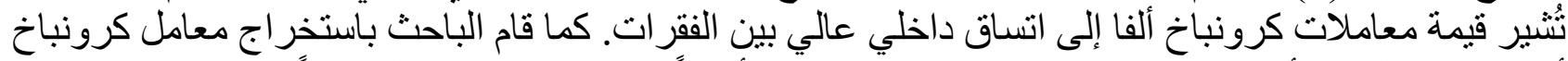

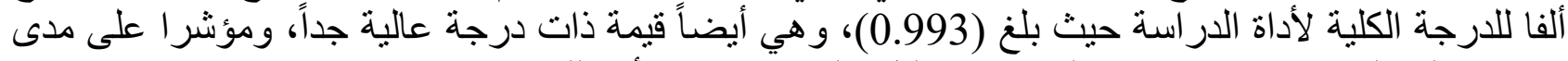
الاتساق الداخلي بين جميع محاور الدر اسة، ودليل على اللى صنلاحية الأداة للتطبيق.

كما تم قياس ثبات الاستبانة باستخدام اختبار (كولموجروف - سميرنوف) للتوزيع الطبيعي ( One-Sample (Kolmogorov-Smirnov Test

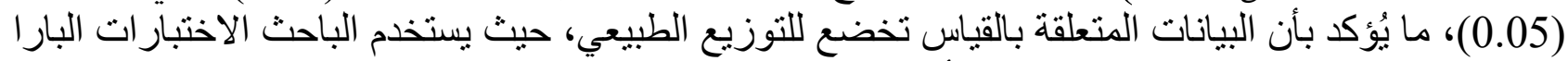

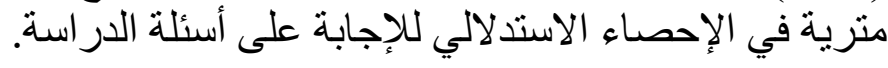




\section{المعالجة الإحصائية للاراسة:}

استخدم الباحث المعالجات الإحصائية والوصفية والتحليلية وفق برنامج الرزمة الإحصائية للعلوم الاجتماعية (SPSS)

أ. معامل الارتباط كرونباخ الفا (AlphaCronbach)؛ للتأكد من صدق وثبات أداة الدر اسة. ب.اختبار كولموجروف - سميرنوف للتوزيع الطبيعي (One-Sample Kolmogorov-Smirnov Test)، للتأكد من اعتدالية البيانات. ت. حساب المتوسطات الحسابية و الانحر افات المعيارية؛ للإجابة على الأسئلة؛ الأول والثاني والثالث. ث. استخدام تحليل الانحدار البسيط و المتعدد، للإجابة على السؤ ال الر ابع.

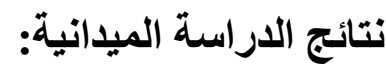

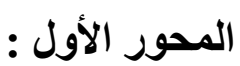
يجيب الدحور بأبعاده على السؤال الأول للار اسة ونصه: "ما هو مستوى رأس المال البشري و الأداء المؤسسي

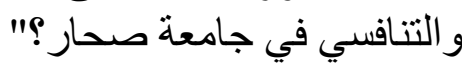

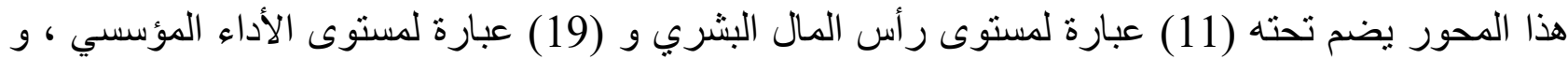

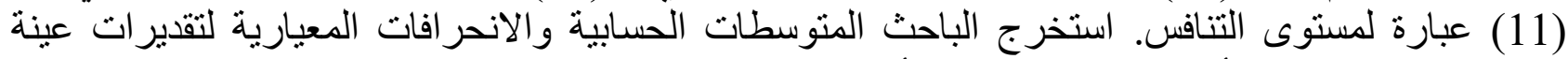

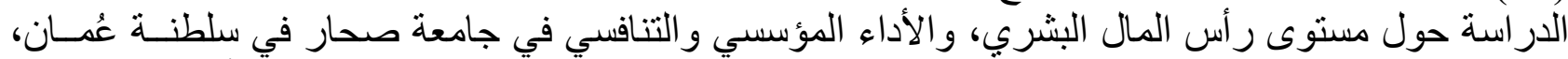

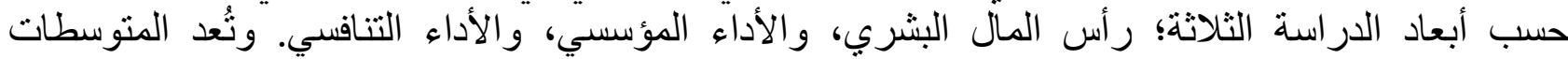

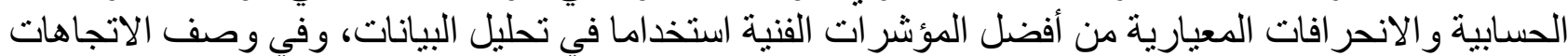

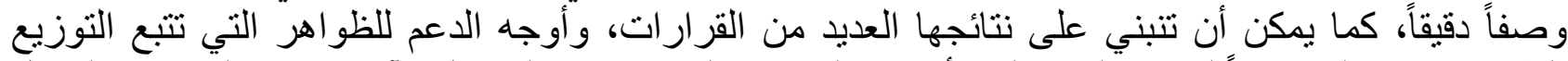

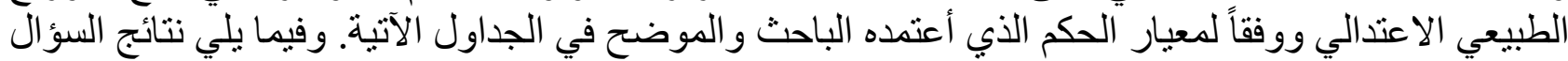

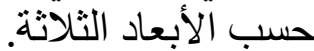

\section{النتائج المتعلقة بمستوى رأس الماد البشة البشري السائد في جامعة صحار:}

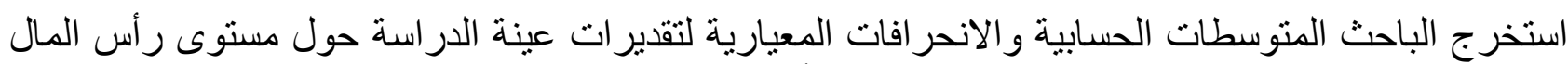

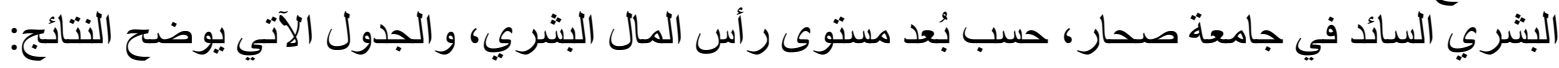

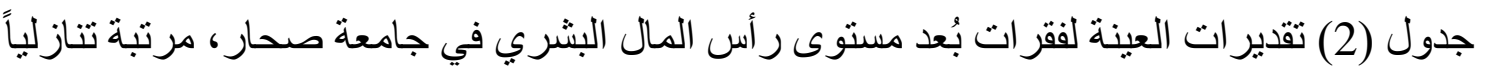

\begin{tabular}{|c|c|c|c|c|c|}
\hline 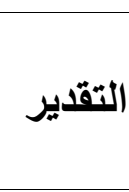 & |لالحرا & المستوسط & 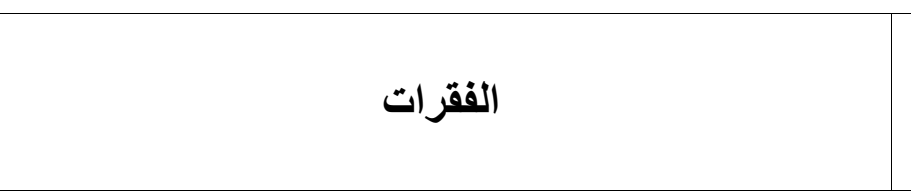 & 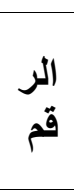 & 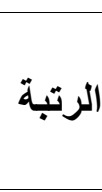 \\
\hline عالية & 1.07 & 3.62 & تر اعلي إدارة الجامعة قدرات العاملين بها عند توزيع مهام & 4 & 1 \\
\hline عالية & 0.93 & 3.56 & تعبيين إدارة الجامعة حملة الثهادات الأكاديمية في الوظائف & 3 & 2 \\
\hline عالية & 0.85 & 3.53 & تسعى إدارة الجامعة إلى الاهتمام بتدريب العاملين لإكسابهح & 6 & 3 \\
\hline عالية & 0.93 & 3.51 & تُعبيين إدارة الجامعة الأفر اد ذوي الخبرات و المهارات & 2 & 4 \\
\hline وسط & 1.25 & 3.38 & تمنلك إدارة الجامعة عاملين لديهم خبر ات فنبة وتقنية عالية & 5 & 5 \\
\hline وسط & 0.74 & 3.38 & قتبل العاملين إدارة الجامعة الأفكار الإبداعية الجديدة الدقدمة من & 9 & 6 \\
\hline
\end{tabular}




\begin{tabular}{|c|c|c|c|c|c|}
\hline وسط & 0.92 & 3.28 & التعاون بين العاملين الجامعة فرق عمل لإنجاز المهام لتحقيق & 11 & 7 \\
\hline وسط & 0.95 & 3.15 & تسعى إدارة الجامعة إلي تقديم حو افز متتوعة تشبع حاجات & 10 & 8 \\
\hline وسط & 1.30 & 3.13 & الجنتشر روح العمل الجماعي و الفريق بين العاملين في & 8 & 9 \\
\hline وسط & 1.26 & 2.82 & و تسعى إدارة الجامعة لاستقطاب الأفر اد ذوي الخبر ات & 1 & 10 \\
\hline وسط & 0.83 & 2.61 & تعتمد إدارة الجامعة في ترقيه العاملين علي تمتعهم & 7 & 11 \\
\hline وسط & 0.47 & 3.27 & المستوى العام & & \\
\hline
\end{tabular}

يبين الجدول (2) تقدير ات عينة الدر اسة حول مستوى رأس المال البشري السائد في جامعة صحار ، حسب بُعد

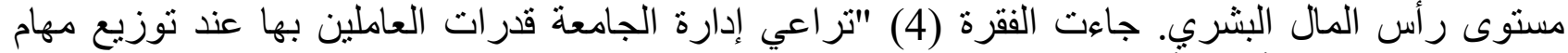

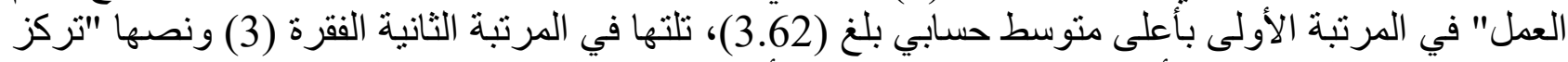

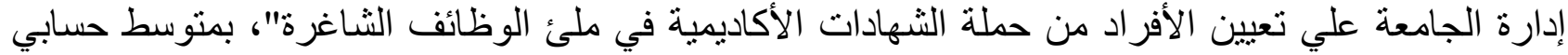

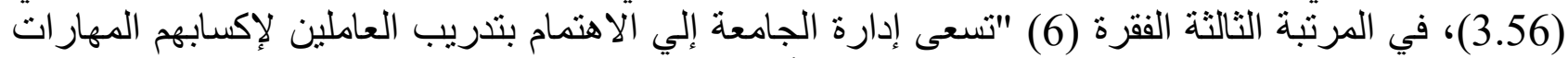

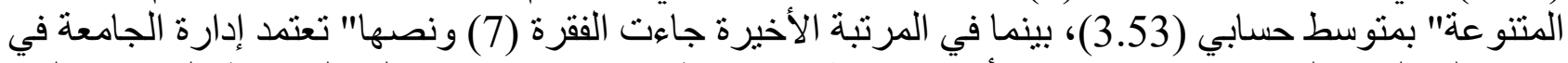
ترقيه العاملين علي تمتعهم بمستويات أداء مرتفعة" بمتوسط حسابي (33) (2.61). بلغ المتوسط الحسابي العام للمحور ككل (3.27)، وبانحر اف معياري عام بلغ (0.47)، أبي بمستوى عام منوسط.

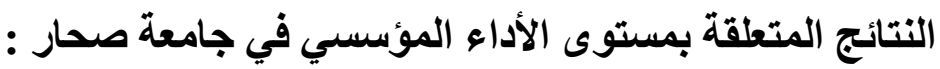
استخرج الباحث المتوسطات الحسابية والانحرافات المعيارية لتقديرات عينة الدراسة حول مستوى الأداء

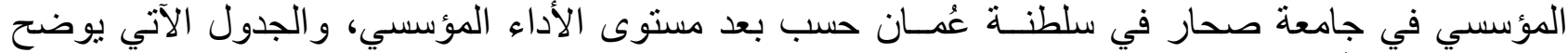
نتائج مستوى الأداء المؤسسي في جامعة في فلمة صحار.

جدول (3) تقدير ات العينة لفقر ات بعد مستوى الأداء المؤسسي في جامعة صحار ، مرتبة تنازلياً

\begin{tabular}{|c|c|c|c|c|c|}
\hline التقدير & الالمعراف إن & المتوسط المبي & 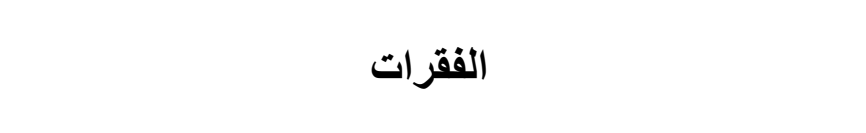 & 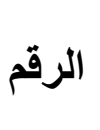 & 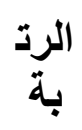 \\
\hline عالية & 1.08 & 3.82 & تتفق إدارة الجامعة مبالغ كبيرة في تحديث نظم & 18 & 1 \\
\hline عالية & 0.94 & 3.62 & تشجع إدارة الجامعة أعضاء هيئة التدريس على النشر & 7 & 2 \\
\hline عالية & 0.99 & 3.55 & تعتمد إدارة الجامعة أساليب تقنية حديثة لإنجاز الأعمال. & 17 & 3 \\
\hline عالية & 0.75 & 3.46 & تحول إدارة الجامعة المعلومات و الأفكار المبتكرة إلى تطبيقية & 2 & 4 \\
\hline عالية & 1.00 & 3.46 & تتم مر اجعة إجر اءات إنجاز الأعمال في الجامعة دوريا. & 11 & 5 \\
\hline طنة & 0.84 & 3.35 & تهنم إدارة الجامعة بتنفيذ استر اتيجياتها بشكل دقيق & 8 & 6 \\
\hline 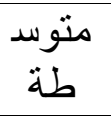 & 1.23 & 3.33 & تدعم إدارة الجامعة مشرو عات هيئة التدريسية لتطوير & 19 & 7 \\
\hline متوسد & 0.98 & 3.25 & تعالج إدارة الجامعة مشاكلها بطرق مبتكرة & 3 & 8 \\
\hline
\end{tabular}


IJASOS- International E-Journal of Advances in Social Sciences, Vol. VI, Issue 17, August 2020

\begin{tabular}{|c|c|c|c|c|c|}
\hline طة & & & & & \\
\hline متوسد & 1.47 & 3.18 & تتسم نظم المعلومات الإدارية في الجامعة بالحداثة. & 14 & 9 \\
\hline 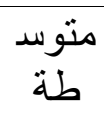 & 0.96 & 3.12 & تسعى إدارة الجامعة إلى أتناص الفرص المتاحة لها لهافيق & 4 & 10 \\
\hline 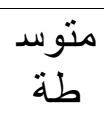 & 0.65 & 3.11 & تدعم إدارة الجامعة بر اءات الاختر اع المقدمة من & 5 & 11 \\
\hline 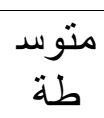 & 1.14 & 3.07 & تعمل إدارة الجامعة طرح استر اتيجيات جديدة لأداء & 1 & 12 \\
\hline 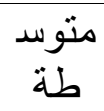 & 0.46 & 3.06 & تسعى إدارة الجامعة إلى تطبيق بر اءات الاختراع & 6 & 13 \\
\hline متوسد & 1.11 & 3.01 & تهنم إدارة الجامعة بجودة الخدمات التي تقدمها لطلابها & 12 & 14 \\
\hline 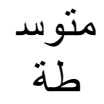 & 1.36 & 3.00 & تتسم نظم المعلومات الإدارية في الجامعة بالدقة. & 15 & 15 \\
\hline 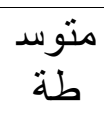 & 1.22 & 2.91 & لدى إدارة الجامعة أنظمة رقابية لقياس جودة الخدمات & 13 & 16 \\
\hline متوسد & 1.20 & 2.64 & تدعم نظم المعلومات الإدارية تنفيذ البر امج و الخطط & 16 & 17 \\
\hline 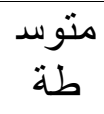 & 1.00 & 2.62 & تهنم إدارة الجامعة بمتابعة أساليب أداء أعمال العاملين & 9 & 18 \\
\hline متوسد & 0.81 & 2.62 & تتسم إجر اءات الجامعة لإنجاز الخدمات بالبساطة. & 10 & 19 \\
\hline متوبد & 0.51 & 3.17 & المستوى العام & & \\
\hline
\end{tabular}

يبين الجدول (3) تقدير ات عينة الدر اسة حول مستوى الأداء المؤسسي في الجامعة، حسب بُعد مستوى الأداء

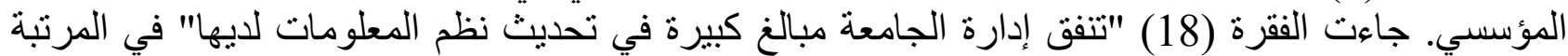

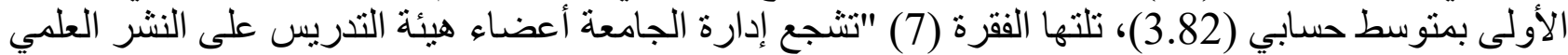

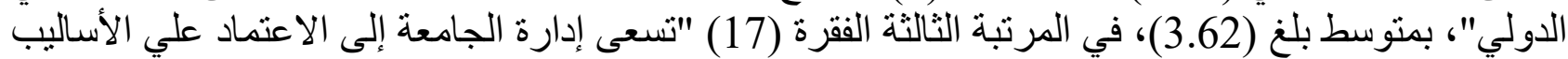

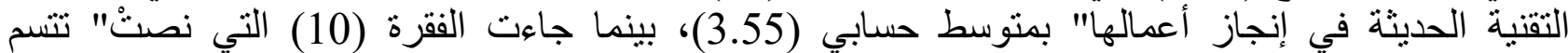

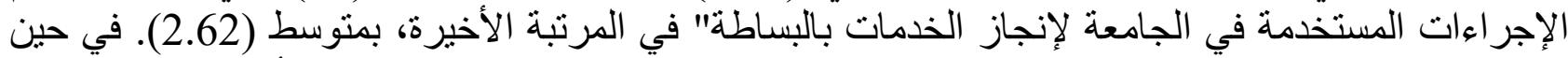
بلغ معدل المتوسط الحسابي العام للمحور ككل (3.17)، وبانحر افت معياري قدره (0.51)، أي بمستوى متوسط فئ للأداء المؤسسي في جامعة صلئ صحار. النتائج المتعلقة بمستوى الأداء التنافسي في جامعة صحار : استخرج الباحث المتوسطات الحسابية والانحرافات المعيارية لتقديرات عينة الدراسة حول مستوى الأداء

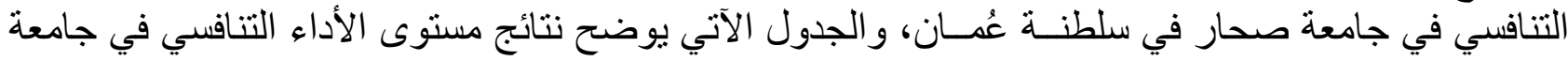
صحار.

جدول (4) تقدير ات العينة لفقر ات بعد مستوى الأداء التنافسي في جامعة صحار ، مرتبة تنازلياً 


\begin{tabular}{|c|c|c|c|c|c|}
\hline 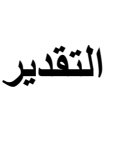 & 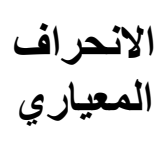 & المستبي & 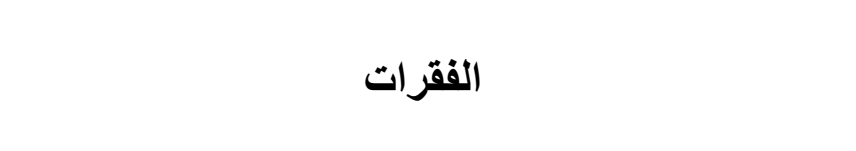 & 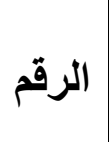 & 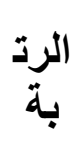 \\
\hline عالية & 0.90 & 3.69 & تخطط إدارة الجامعة من أجل الحصول على جو ائز & 5 & 1 \\
\hline عالية & 0.98 & 3.69 & تهتم إدارة الجامعة بمشاكل الطلاب ومعالجتها بشكل & 11 & 2 \\
\hline عالية & 1.00 & 3.62 & تسعى إدارة الجامعة لتطوير خططها المستقبلية & 10 & 3 \\
\hline عالية & 1.07 & 3.54 & تستجيب إدارة الجامعة لحاجات سوق العمل بفتح & 9 & 4 \\
\hline عالية & 1.00 & 3.47 & تعتمد إدارة الجامعة إدارة المعلومات بشكل مميز & 8 & 5 \\
\hline عالية & 1.06 & 3.46 & تضع إدارة الجامعة معايير الميزة التنافسية خاصة بها. & 1 & 6 \\
\hline عالية & 1.07 & 3.46 & تستجيب إدارة الجامعة بسر عة للنطورات في مجال & 7 & 7 \\
\hline عالية & 1.00 & 3.40 & تشجع إدارة الجامعة العاملين فيها على الارتقاء & 2 & 8 \\
\hline 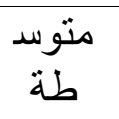 & 0.91 & 3.32 & تتميز إدارة الجامعة بمقدرة عالية على الاستجابة لخدمة & 6 & 9 \\
\hline 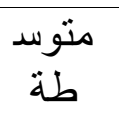 & 1.10 & 3.25 & تعمل إدارة الجامعة بالتعاون مع جامقين الجودة أخرى على على تحقيق & 4 & 10 \\
\hline 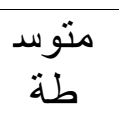 & 1.02 & 3.17 & 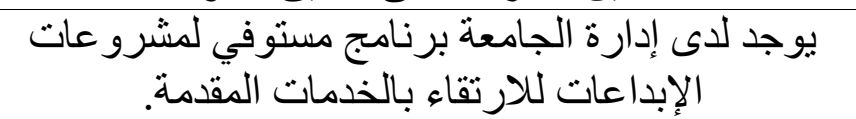 & 3 & 11 \\
\hline عالية & 0.90 & 3.46 & المستوى العام & & \\
\hline
\end{tabular}

يبين الجدول (4) تقديرات عينة الدراسة حول مستوى الأداء التنافسي في الجامعة حسب بُعد مستوى الأداء

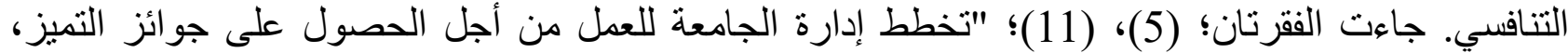

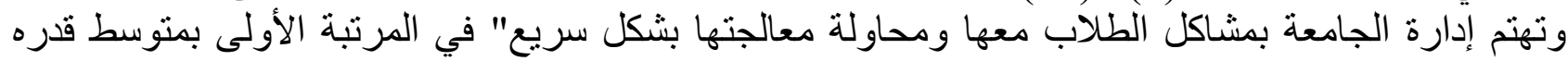

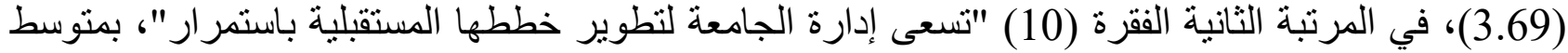

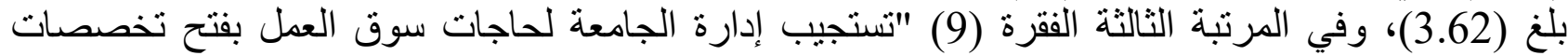

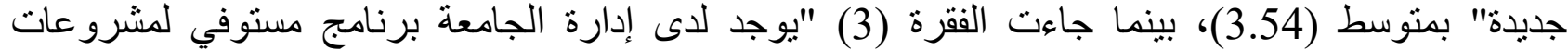

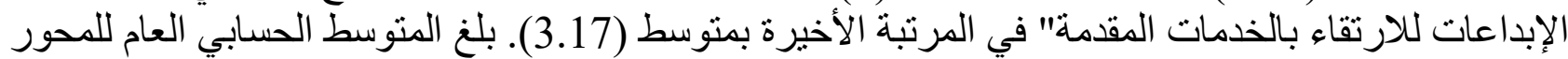

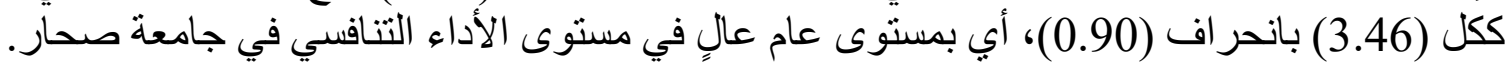

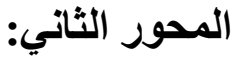

يجيب المحور الثاني على السؤال الثناني للار اسة ونصاه: "ما مستوى مؤهلات رأس المال البشري في جامعة

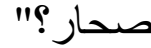

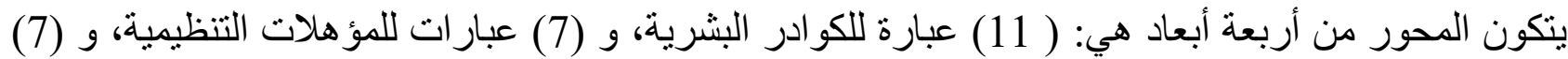

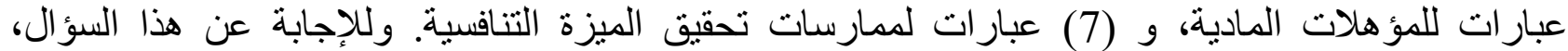

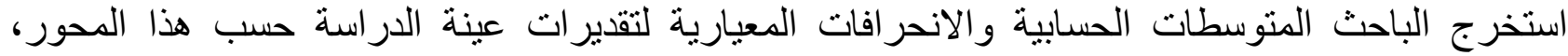

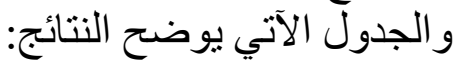


جدول (5) تقدير ات العينة لأبعاد محور مؤ هلات رأس المال البشري، مرتبة تنازلياً

\begin{tabular}{|c|c|c|c|c|c|}
\hline التقدير & الالنحرياري & المستوسط المسي & الأبعاد & 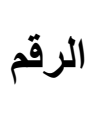 & الرتبة \\
\hline متوسطة & 0.55 & 3.38 & بُعد المؤهلات البشرية & 1 & 1 \\
\hline متوسطة & 0.45 & 3.24 & بُعد المؤهلات المادية & 3 & 2 \\
\hline متوسطة & 0.52 & 3.21 & بُعد المؤ هلات التتظيمبة & 2 & 3 \\
\hline متوسطة & 0.38 & 3.28 & المستوى العام & & \\
\hline
\end{tabular}

يبين الجدول (5) تقدير ات عينة الدراسة حول مستوى مؤهلات رأس المال البشري في الجامعة، حسب محور

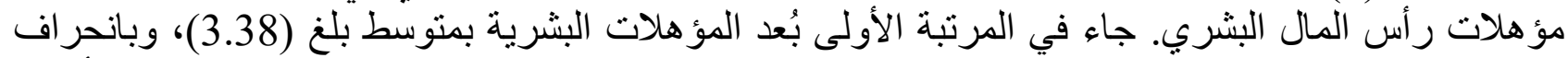

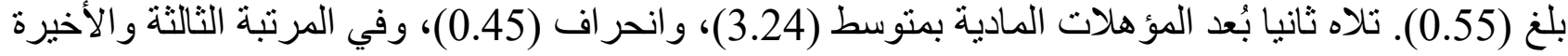

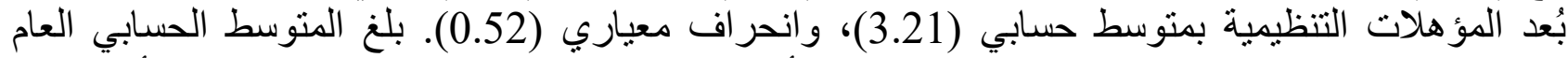

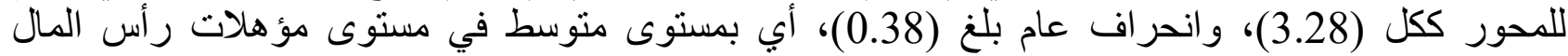

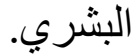

أ: النتائج المتعلقة ببُعد المؤهلات البشرية:

جدول (6) تقدير ات العينة لفقر ات المؤهلات البشرية، مرتبة تنازلياً

\begin{tabular}{|c|c|c|c|c|c|}
\hline التقدير & الانحرا & المتوسط المبي & 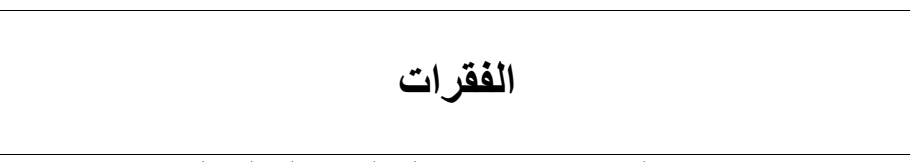 & 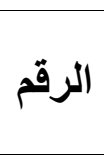 & 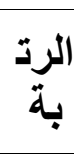 \\
\hline عالية & 1.05 & 3.71 & توفر إدارة الجامعة فرص التعليم و التعلم المستمر. & 1 & 1 \\
\hline عالية & 1.07 & 3.62 & تحرص إدارة الجامعة على تكريس العمل بروح التريسة الفريق بين & 11 & 2 \\
\hline عالية & 0.93 & 3.56 & تحفز إدارة الجامعة العاملين بها على المساهمة في أنشطة البئة & 10 & 3 \\
\hline عالية & 0.99 & 3.55 & تقبس إدارة الجامعة رضا المستقيدين من خلال الخدمات. & 3 & 4 \\
\hline عالية & 0.92 & 3.55 & 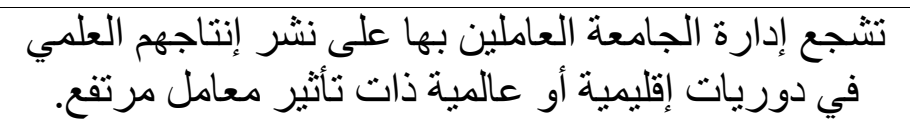 & 5 & 5 \\
\hline عالية & 0.92 & 3.54 & تحثث إدارة الجامعة العاملين بها على المشاتية الدوكة في & 6 & 6 \\
\hline عالية & 0.93 & 3.51 & 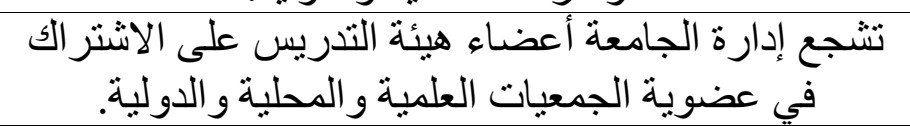 & 9 & 7 \\
\hline 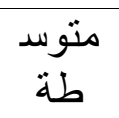 & 1.22 & 3.25 & تمكين أَعضاء هيئة التذريس ومنحهم الصـالاحيات اللازمة ألتفار هم الابتكارية. & 2 & 8 \\
\hline 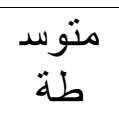 & 1.03 & 3.25 & 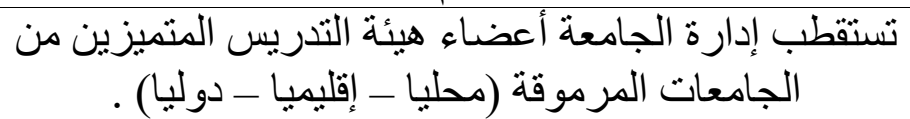 & 7 & 9 \\
\hline 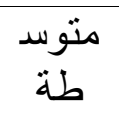 & 1.00 & 2.84 & 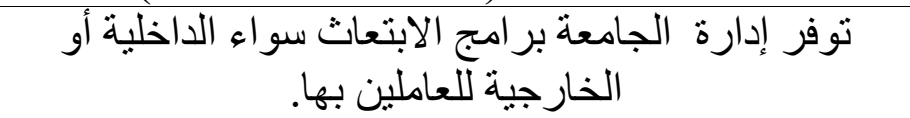 & 4 & 10 \\
\hline 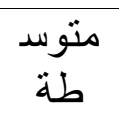 & 1.26 & 2.82 & 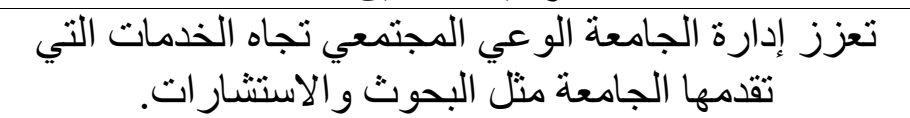 & 8 & 11 \\
\hline 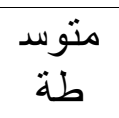 & 0.55 & 3.38 & المستوى العام & & \\
\hline
\end{tabular}


يبين الجدول (6) المتوسطات الحسابية والانحر افات المعيارية لفقرات محور المؤهلات البشرية، إذ بلغ المتوسط

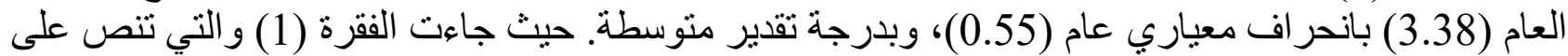

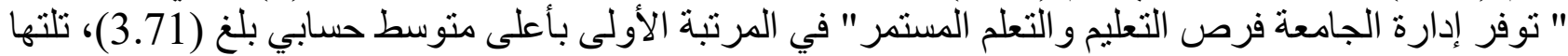
في المرتبة الثانية الفقرة (11) ونصها" تحرص إنة فئة إدة الجامعة على تكريس العمل بروح الفريق بين أعضاء

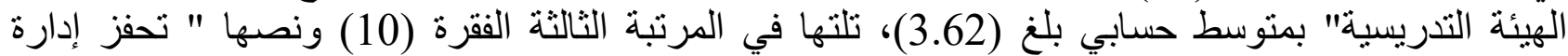

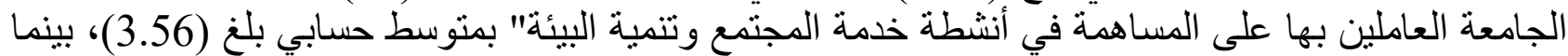
جاءت الفقرة (8) ونصها" تعزز إدارة الجامعة الوعي المجتمعي تجاه الخدمات التي تقدمها الجامة الجامعة مثل البحوث والاستشنار ات" في المرتبة الأخيرة بمنتوسط حسابي بلَّ (2.82).

النتائج المتعلقة بالمؤهلات التنظيمية:

الجدول (7) المتوسطات الحسابية و الانحر افات المعيارية لفقر ات المؤ هلات التنظيمية، مرتبة تنازلياً

\begin{tabular}{|c|c|c|c|c|c|}
\hline التقدير & 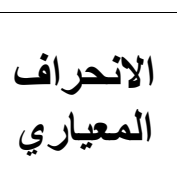 & المتوسد & الفقرات & الرقم & الرتبة \\
\hline عالية & 0.85 & 3.53 & تطوليا. إدارة الجامعة نظم الدر اسة لجذب الطلاب محليا و & 2 & 1 \\
\hline طة متوس & 1.25 & 3.38 & المعور إدارة الجامعة هيكلها التنظيمي بما يسمح بتدفق & 1 & 2 \\
\hline طنة & 0.74 & 3.38 & تضكرعة إدارة الجامعة آليات للحفاظ على حقوق الملكية & 5 & 2 \\
\hline متوسد & 0.92 & 3.28 & تظور إدارة الجامعة نظم تقييم أداء العاملين بها. & 7 & 3 \\
\hline طنة & 0.95 & 3.15 & تربط الجامعة خطتها البحثية بخطط التنمية وحاجات & 6 & 4 \\
\hline متوسد & 1.30 & 3.13 & تحرص إدارة الجامعة على نشر ثقافة تتظيمية ترسيخ قيم & 4 & 5 \\
\hline متوسد & 0.83 & 2.61 & 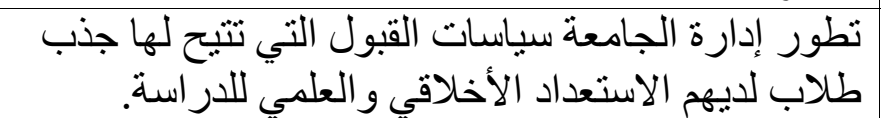 & 3 & 6 \\
\hline متة مبد & 0.52 & 3.21 & المستوى العام & & \\
\hline
\end{tabular}

يبين الجدول (7) نتائج فقر ات محور المؤهلات التنظيمية، إذ بلغ المتوسط العام (3.21) بانحر اف معياري عام

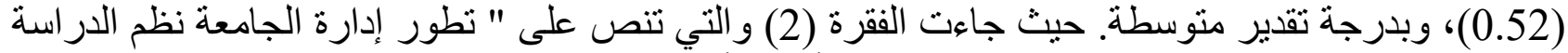
لجذب الطلاب الو افدين محليا و دوليا" في المرتبة الأولى بأعلى متوسط حسابي بلغ (32) (3.53)، تلتها في المرتبة

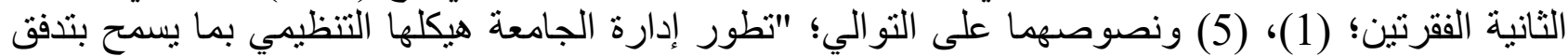

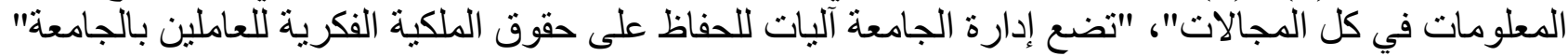

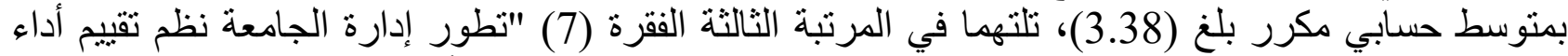

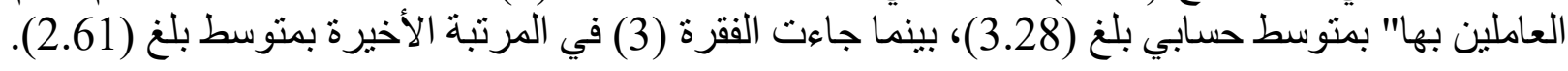

النتائج المتعلقة بالمؤهلات المادية: 
الجدول (8) تحليل استجابات العينة لفقر ات المؤهلات المادية مرتبة تتازلياً

\begin{tabular}{|c|c|c|c|c|c|}
\hline 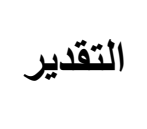 & 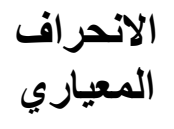 & المستبي & 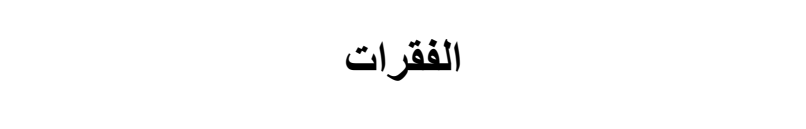 & 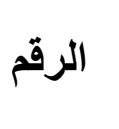 & 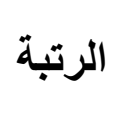 \\
\hline عالية & 0.94 & 3.62 & وإثراء المكتبة بأحدث المر اجع و الدوريات العربية & 7 & 1 \\
\hline عالية & 0.75 & 3.46 & تجهيز مباني الجامعة وفق معايير إدارة الجودة . & 2 & 2 \\
\hline 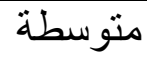 & 0.98 & 3.25 & تخصيص ميز انية كافية للمهمات العلمية. & 3 & 3 \\
\hline متوسطة & 0.96 & 3.12 & توفير المخصص التعليح. & 4 & 4 \\
\hline متوسطة & 0.65 & 3.11 & 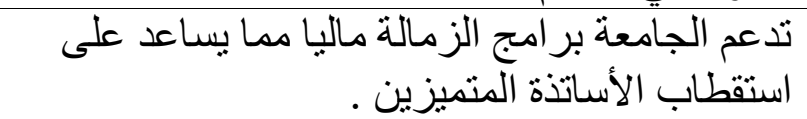 & 5 & 5 \\
\hline متوسطة & 1.14 & 3.07 & التدريبية. تقنيات التعليم و التعلم الحديثة في القاعات & 1 & 6 \\
\hline متوسطة & 0.46 & 3.06 & تلتوفيب ألدضماء هيئة التدريس. لاستقطاب مدربين مؤهلين & 6 & 7 \\
\hline متوسطة & 0.45 & 3.24 & المستوى العام & & \\
\hline
\end{tabular}

يبين الجدول (8) المتوسطات الحسابية والانحر افات المعيارية لفقرات بُعد المؤهلات المادية، إذ بلغ الهتوسط

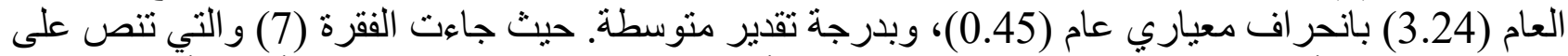

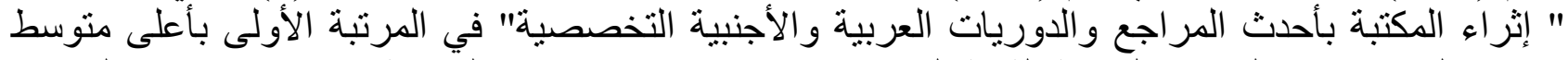

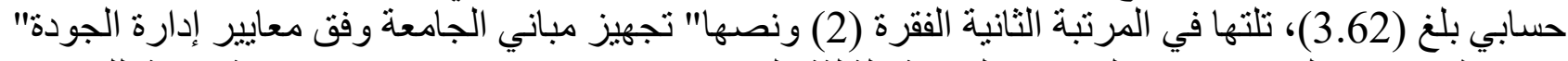

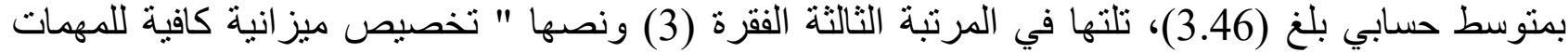

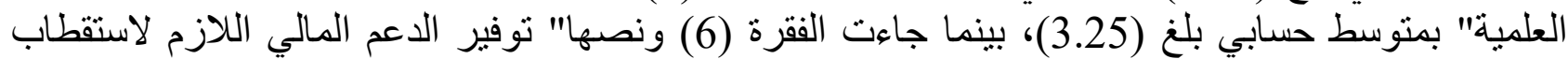
مدربين مؤهلين لندريب أعضاء هيئة التدريس" في المرتبة الأخيرة بمتوسط حسابي بلغ (3.06).

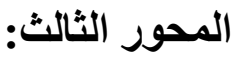

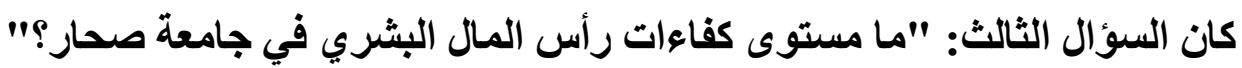

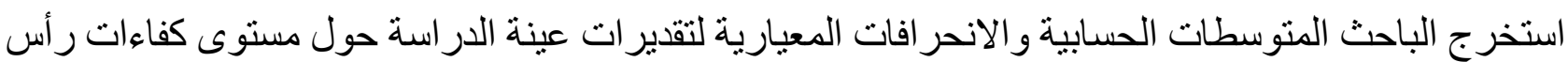

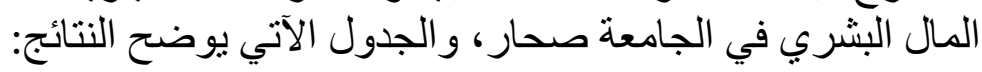

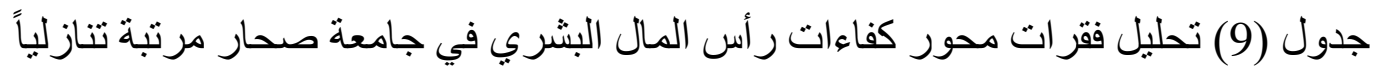

\begin{tabular}{|c|c|c|c|c|c|}
\hline التقدير & المعياري & الحستوبي & 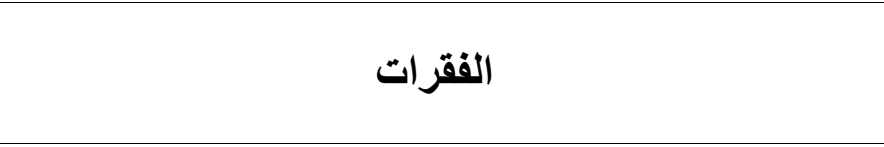 & 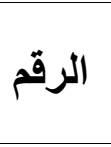 & 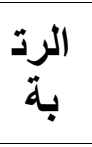 \\
\hline عالية & 1.08 & 3.82 & تؤثر القيم السائدة في الجامعة على جودة الأداء المؤسسي. & 4 & 1 \\
\hline عالية & 1.05 & 3.71 & وتطوير الأداء الجزاءٔسسى المعتمد في الجامعة في تحسين & 17 & 2 \\
\hline عالية & 0.90 & 3.69 & 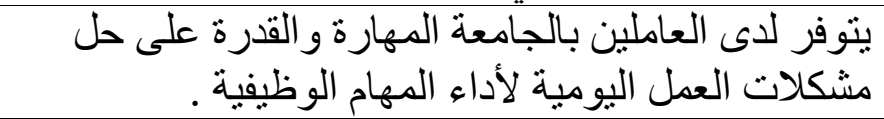 & 10 & 3 \\
\hline عالية & 0.98 & 3.69 & العاملين في الجامعة تلقداء المؤسسي بتحديد طبيعة ونو عية أداء & 16 & 4 \\
\hline
\end{tabular}


IJASOS- International E-Journal of Advances in Social Sciences, Vol. VI, Issue 17, August 2020

\begin{tabular}{|c|c|c|c|c|c|}
\hline عالية & 1.00 & 3.62 & توجد معرفة لدى العاملين بطبيعة الأعمال الموكلة إليهح. & 15 & 5 \\
\hline عالية & 0.99 & 3.55 & تسعهم السياسات و الإجر اءات المتبعة في الجامعة في تحقيق & 3 & 6 \\
\hline عالية & 0.99 & 3.55 & لدى الموظد نظام تقييم الأداء الوظيفي نقاط القوة ونقاط الضعف & 19 & 7 \\
\hline عالية & 0.92 & 3.55 & لتشوير وتحسين أدائهم الوظيفي الأداء حافز اللعاملين ذوي التقييم المتدني & 21 & 8 \\
\hline عالية & 1.07 & 3.54 & 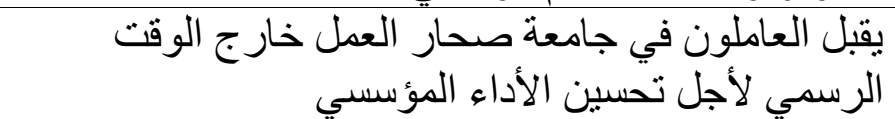 & 14 & 9 \\
\hline 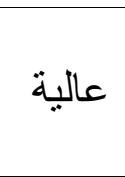 & 0.92 & 3.54 & 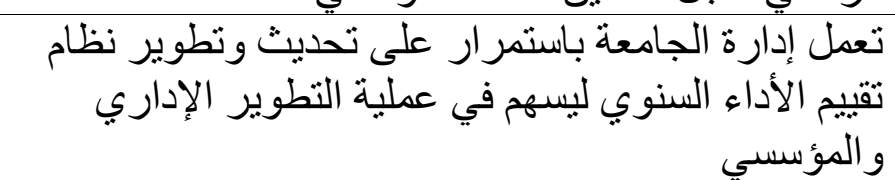 & 22 & 10 \\
\hline عالية & 1.00 & 3.47 & 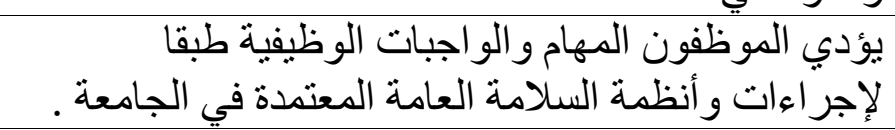 & 13 & 11 \\
\hline عالية & 1.06 & 3.46 & المؤثر الأنماط السلوكية للعاملين في الجامعة على الأداء & 6 & 12 \\
\hline عالية & 1.07 & 3.46 & 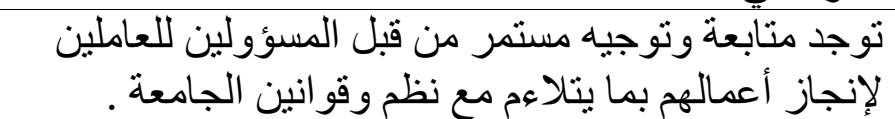 & 12 & 13 \\
\hline عالية & 1.00 & 3.40 & تألساهم الأنظمة و اللو ائح المعتمدة في الجامعة في تطوير & 7 & 14 \\
\hline وسط & 1.23 & 3.33 & 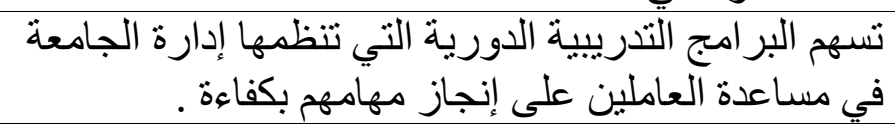 & 5 & 15 \\
\hline وسط & 0.91 & 3.32 & المؤسق إدارة الجامعة بين المستويات الإدارية لتحسين الأداء & 11 & 16 \\
\hline وسط & 1.10 & 3.25 & تألاد إدارة الجؤسمية . باقتر احات العاملين الخاصة بتحسين & 9 & 17 \\
\hline وسط & 1.22 & 3.25 & 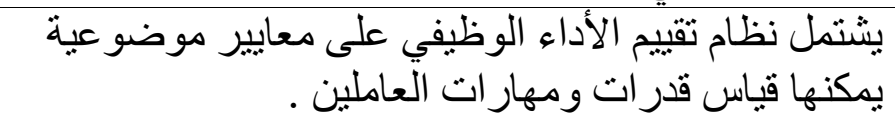 & 18 & 18 \\
\hline وسط & 1.02 & 3.17 & في تحسينم المعتقدات والأداء المؤسكار السائدة لدى العاملين في الجامعة . & 8 & 19 \\
\hline وسط & 1.36 & 3.00 & المؤدي العاملون في الجامعة أعمالهم طبقا لمعايير الجودة & 1 & 20 \\
\hline وسط & 1.00 & 2.84 & تتثم الاستفادة من نتائج تقييم الأداء في عملية تحديد البر امج & 20 & 21 \\
\hline وسط & 1.20 & 2.64 & يقوم العاملون في الجامعة بتأدية أعمالهم بالكفاءة و الفاعلية & 2 & 22 \\
\hline عالية & 0.82 & 3.40 & المستوى العام الع & & \\
\hline
\end{tabular}

يبين الجدول (9) المتوسطات الحسابية والانحر افات المعيارية لتقديرات عينة الدراسة حول مستوى كفاءات

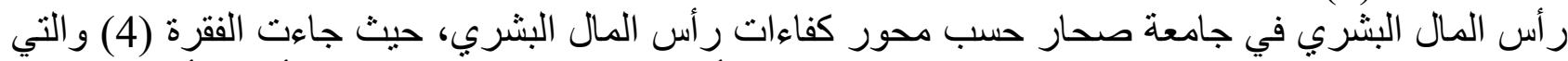

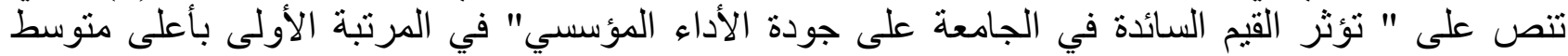

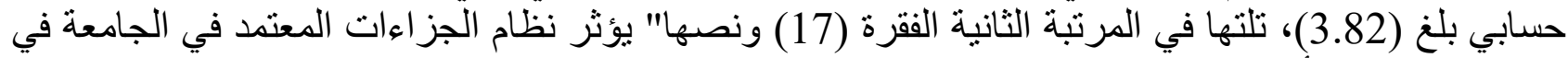

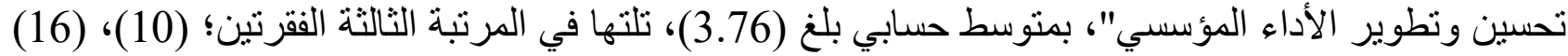


ونصوصهما على التو الي؛ " يتوفر لدى العاملين بالجامعة المهارة و القدرة على حل مشكلات العمل اليومية لأداء

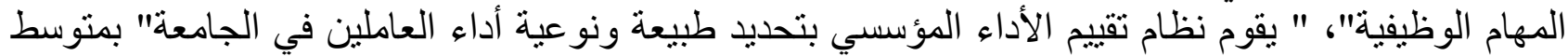

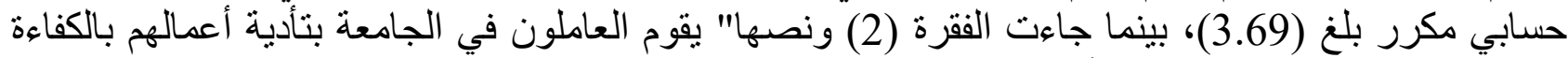

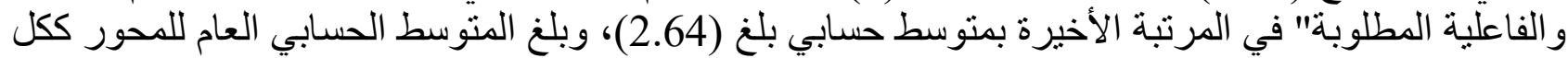
(3.40)، وبانحر اف معياري عام بلغ (0.82)، أي بمستوى عام عالٍ في كفاءات رأس المال البشري في في جامعة المبة

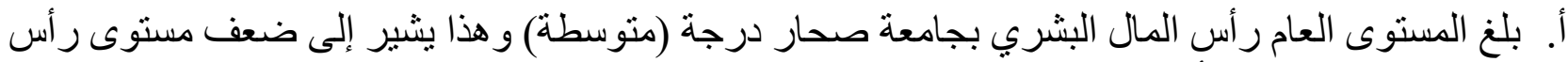
المال البشري، واعتماد الأساليب التقليديةٌ في إدارته، و غياب استر اتيجية استقطاب و المحافظة ولئة على الموارد البشرية.

ب.بلغ المستوى العام درجة (متوسطة) في مستوى الأداء المؤسسي بجامعة صحار ، و هذا بدل على اهتمام

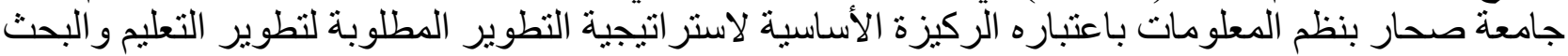

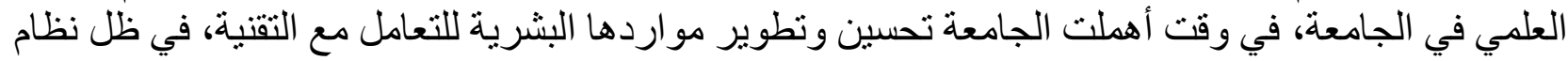

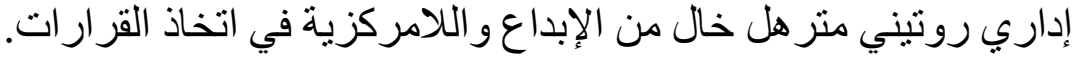

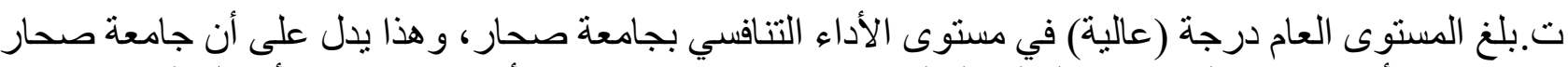

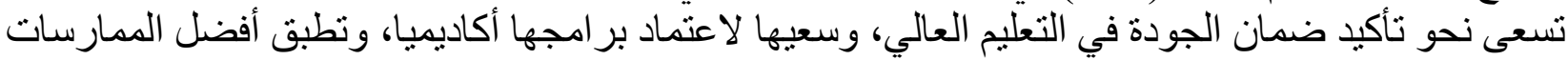

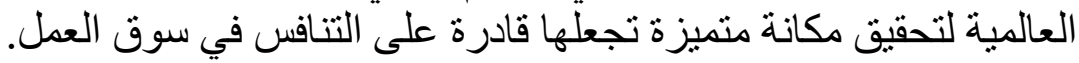

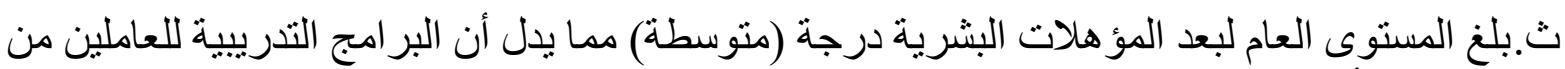

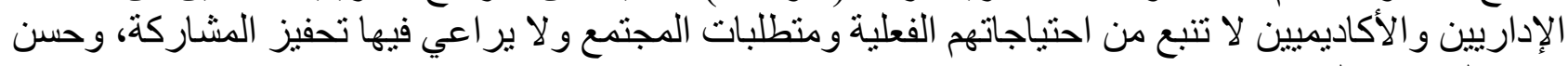
انتقاء القائمين بالتدريب.

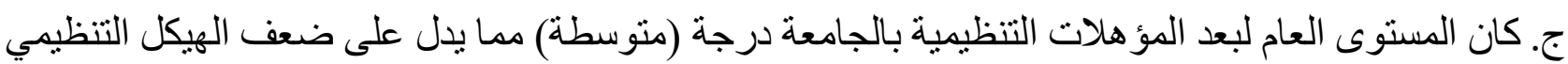

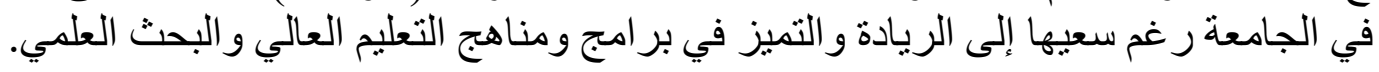

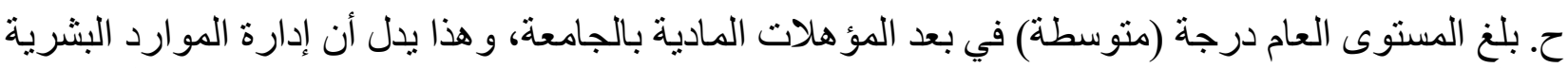

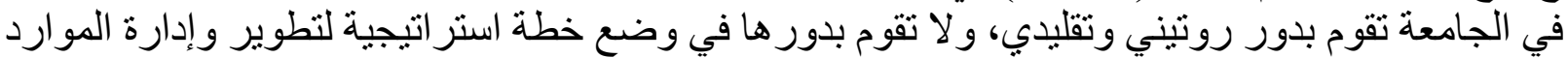
البشرية، تنسجم مع التطلعات العالمية وتو اكب المستجدات و التغيرات التي تطر أ على عالم الإدارة لتحقيق الجودة التعليمية.

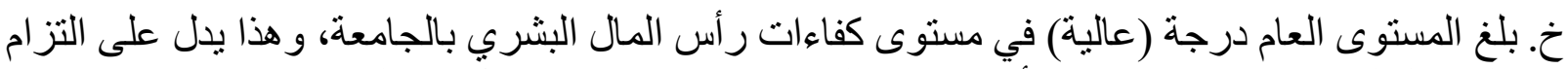

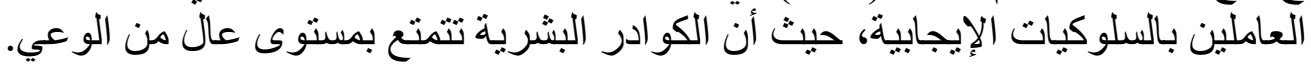

قائمة المراجع:

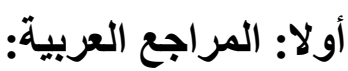
أبو بكر ، آسيا داؤود.(2016) ـ أثر إدارة الموارد البشرية على الأداء المؤسسي : دراسة تطبيقية على وزارة

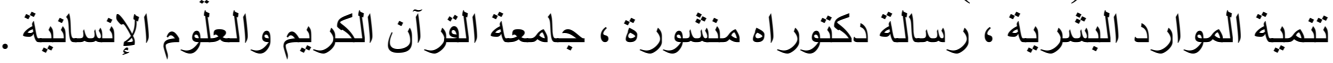
بخيت، عادل حسن (2010). الجودة وتتمية وتدريب الموارد البشرية: در اسة تطبيقية على قطاع التعليم العالي

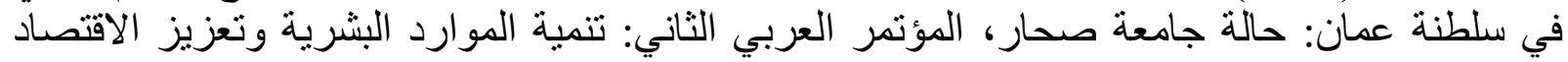


الوطني.

بور اس، فايزة. (2018). الاستثمار في رأس المال البشري كمدخل لاكتساب الميزة التنافسية المستدامة في

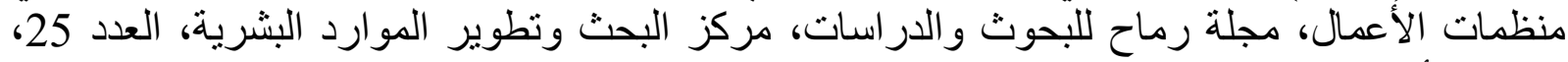
رماح، الأردن.

دريد، عبد الغني (2015). الاستثمار في رأس المال البشري ودوره في تطوير أداء العاملين بالمكتبات الجامعية:

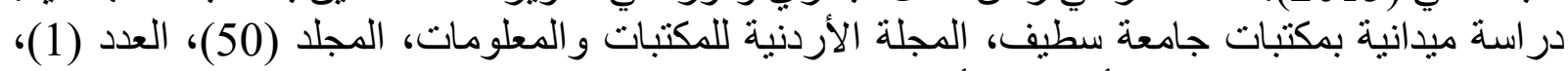
جمعية المكتبات و المعلومات البات الأردنية، الأردن.

الدوري، كريا مطلق. (2005). الإدارة الاسنراتيجية مفاهيم وعمليات وحالات دراسية، عمان: دار اليازوري للنشر، 2005م. كربا مطاق.

رشاد، عبد الناصر عحد \& حباكة، أمل سعيد حمد (2017): تطوير الأداء المؤسسي وتحقيق الميزة التنافسية

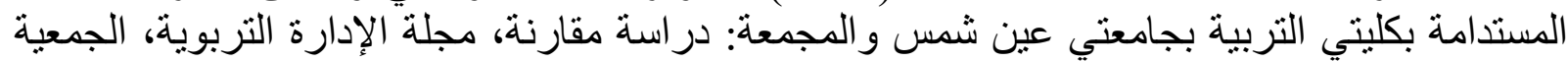

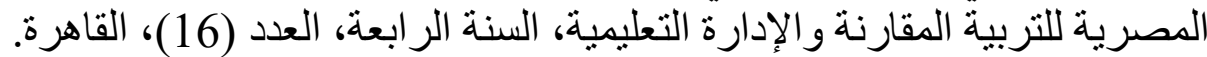

شهاب، فادية إبر اهيم ححم، أبو عاثور ، خليفه مصطفى. (2017). إدارة الموارد البشرية في الجامعات الخاصة في الأردن و الأداء المؤسسي: الوافئ الع و المأمول، مجلة دراسات في العلوم التربوية، المجلد 44، الأردن. العلي، عبد الستار وآخرون. (2006م). المدخل إلى إدارة المعرفة، ط1، عمان: دار المسيرة. القاسمية، عايدة بنت بطي بن راشد والعمرية، مريم بنت سعيد بن ححم. (2018). التنمية المهنية و علاقتها بمستوى الرضا الوظيفي لدى موظفي جامعة صحار، لمجلد (34)، العدد (6)، بندة جامعة أسيوط، كلية التربية، ص - 247-517.

محمود، شيرين حمح وسيم (2017). إدارة رأس المال الفكري: مدخل لتعزيز القدرة التنافسية لكليات التربية

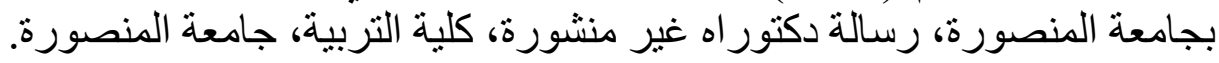

المرسي، جمال الدين (2003). الإدارة الاستر اتيجية للموارد البشرية، الإسكندرية: الدار الجامعية. مصطفى، أحمد سيد. (2000). إدارة الموارد البشرية منظور القرن الحادي والعثرين، ط1، القاهرة: دار

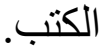

المطيري ، عزيز عبد الله.(2016) ـ أثر استراتيجيات إدارة الموارد البثرية في الأداء الوظيفي : در اسة تطبيقية

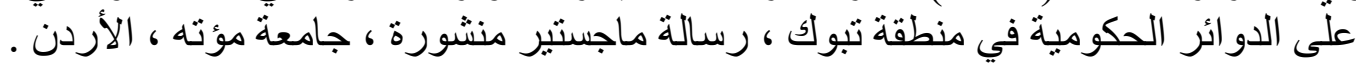

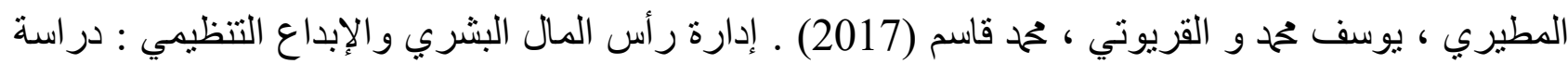
ميدانية لبعض الجهات الحكومية في دولة الكويت ، المجلة العربية للعلوم الإدارية ، المجلد (249 ،

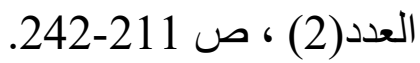

المعموري، عثمان طالب عبد الكريم. (2015). أثر إدارة الجودة الثاملة على الأداء المؤسسي: دراسة حالة، الثان. رسالة ماجستير منشورة، كلية الأعمال، جامعة عمان العربية، العارة الأردن.

المغربي، عبد الحميد عبد الفتاح (2007): الإدارة الاستراتيجية بقياس الأداء المتوازن، المنصورة: المكتبة العصرية.

مؤسسة مححد بن راشد آل مكتوم (2018). الابتكار وليد القطاع الخاص والتنافسية سر الريادة العالمية، مجلة

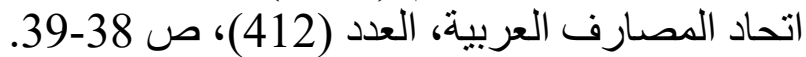

\section{ARABIC REFERENCES IN ROMAN ALPHABET}

'Abu Bakr, Asia Dawuwd. (2016). 'Athar 'lidarat Almawarid Albashariat Ealaa Al'ada' Almuasisii: Dirasatan Tatbiqiatan Ealaa Wizarat Tanmiat Almawarid Albashariat, Risalatan Dukturah Manshuratan, Jamieat 
Alquran Alkarim Waleulum Al'iinsania.

Bakhayt, Eadil Hasan (2010). Aljawdat Watanmiat Watadrib Almawarid Albashariati: Dirasatan Tatbiqiat Ealaa Qitae Altaelim Aleali fi Saltanat Eaman: Halat Jamieat Suhari, Almutamar Alearabii Althaani: Tanmiat Almawarid Albashariat Wataeziz Alaiqtisad Alwatani.

Buras, Fayzt. (2018). Alaistithmar fi Ras Almal Albasharii Kamadkhal Liaiktisab Almayazat Altanafusiat Almustadamat fi Munazamat Al'aemali, Majalat Ramah Lilbihawth Waldirasati, Markaz Albahth Watatwir Almawarid Albashariatu, Aleadad 25, Ramahi, Al'urdunn.

Darid, Eabd Alghaniu (2015). Alaistithmar fi Ras Almal Albasharii Wadawrih fi Tatwir 'Ada' Aleamilin Bialmuktabat Aljamieiat: Dirasat Maydaniat Bimuktabat Jamieat Satifi, Almajalat Al'urduniyat Lilmuktabat Walmaelumati, Almujalid (50), Aleadad (1), Jameiat Almaktabat Walmelwmat Al'urduniyati, Al'urdunn.

Aldawri, Karia Matluq. (2005). Al'iidarat Al'iistiratijiat Mafahim Waeamaliat Wahalat Darasiatun, Eamana: Dar Alyazury Lilnushr.

Rashad, Eabd Alnnasir Muhamad \& Hibakat, 'Amal Saeid Muhamad (2017): Tatwir Al'ada' Almuasisii Watahqiq Almayazat Altanafusiat Almustadamat Bikaliati Altarbiat Bijamieatay Eayan Shams Walmujmet: Dirasat Muqarinati, Majalat Al'iidarat Altarbawiati, Aljameiat Almisriat Liltarbiat Almuqaranat Wal'iidarat Altaelimiati, Alsanat Alraabieat, Aleadad (16), Alqahirat.

Shahab, Fadiat 'librahim Muhamd, 'Abu Eashur, Khalifh Mustafaa. (2017). 'lidarat Almawarid Albashariat fi Aljamieat Alkhasat fi Al'urdun Wal'ada' Almwssy: Alwaqie Walmamuli, Majalat Dirasat fi Aleulum Altarbawiati, Almujalid 44, Al'urdunn.

Aleali, Eabd Alsitar Wakharawn. (2006ma). Almudkhil 'lilaa 'lidarat Almuerifati, Ta1, Eamana: Dar Almasirat. Alqasimiatu, Eayidat Bnt Bitay Bin Rashid Waleimriatu,

Maryam Bnt Saeid Bin Mahmd. (2018). Altanmiat Almihniat Waealaqatuha Bimustawaa Alrada Alwazifii Ladaa Muazafi Jamieat Suharin, Limujalid (34), Aleadad (6), Jamieat 'Usyawt, Kuliyat Altarbiat, S 447517.

Muhmud, Shyryn Muhamad Wasaym (2017). 'lidarat Ras Almal Alfkry: Madkhal Litaeziz Alqudrat Altanafusiat Likuliyat Altarbiat Bijamieat Almansurati, Risalat Dukturah Ghyr Manshurati, Kuliyat Altarbiati, Jamieat Almansurat.

Almarsi, Jamal Aldiyn (2003). Al'iidarat Al'iistiratijiat Lilmawarid Albashariati, Al'iiskandariatu: Aldaar Aljamieiat.

Mastafaa ،'Ahmad Sayd. (2000). 'lidarat Almawarid Albashariat Manzur Alqarn Alhadi Waleishriun, t1, Alqahrt: Dar Alkutb.

Almutayri, Eaziz Eabd Allah. (2016) . 'Athara Aistiratijiat 'lidarat Almawarid Albashariat fi Al'ada' Alwazifii: Dirasatan Tatbiqiatan Ealaa Aldawayir Alhukumiat fi Mintaqat Tbwk, Risalat Majstyr Manshuratan, Jamieatan Mutah, Al'urdunu.

Almutayri, Yusif Muhamad W Alqariuti, Muhamad Qasim (2017). 'lidarat Ras Almal Albasharii Wal'iibdae Altanzimii: Dirasatan Maydaniatan Libaed Aljihat Alhukumiat fi Dawlat Alkuayt, Almajalat Alearabiat Lileulum Al'iidariat, Almajlid (249, Aleidda (2), S 211-242.

Almaemuri, Euthman Talab Eabd Alkarim. (2015). 'Athar 'lidarat Aljawdat Alshshamilat Ealaa Al'ada' Almwssy: Dirasat Halati, Risalat Majstayr Manshurat, Kuliyat Al'aemali, Jamieat Eamman Alearabiatu, Al'urdunn.

Almaghribi, Eabd Alhamid Eabd Alfattah (2007): Al'iidarat Al'iistiratijiat Biqias Al'ada' Almutawazini, Almnsurat: Almuktabat Aleasriati.

Muasasat Muhamad Bin Rashid Al Maktum (2018). Alaibtikar Walid Alqitae Alkhasi Waltanafusiat Sira Alryadt Alealamiati, Majalat Aitihad Almasarif Alearabiat, Aleadad (412), S 38-39.

\section{REFERENCES}

David Draper, Mark Gittoes. (1999). Statistical Analysis of Performance Indicators in UK Higher Education; (UK: HEFCE in December .3.

Jamal, Waseem. (2011). Impact of Human Capital Management on Organizational Performance, European Journal of Economic, Finance and Administrative Sciences, 34, 55-69. 
Long-Sheng Lin, Ing-Chung Huang, Pey-Lan Du, Tsai-Fei Lin. (2012)."Human capital disclosure and organizational performance: The moderating effects of knowledge intensity and organizational size", Management Decision, Vol. 50 Issue: 10, 1790-1799.

Marimuthu, Maran, ArokiasAmy, Lawrence \& Ismail (2009). Human Capital Development and its impact on Firm Performance, Evidence from Developmental Economics, Dergisi, Journal of International Social Research Volume 2 (8)

Memon M \& Mangi, R \& Rohra, C. (2009). Human Capital a Source of Competitive advantage: Ideas for Strategic Leadership, Australian Journal of Basic \& Applied Sciences, (3), (4).

Nich Bontis Jac Fitz - enz. (2002). "Intellectual Capital ROI: a causal map of human capital antecedents and consequents", Journal of Intellectual capital Bradford, Vol,3 Iss.3 223-225.

Souleh, Samah. (2014). The Impact of Human Capital Management on the innovativeness of research center: the case of scientific Research Centers in Algeria, International journal of Business and Management, 2(4).

Tabiu, Abubakar. (2013). Assessing the Effects of Human Resource Management (HRM)Practices on Employee Job Performance: A study of Usmanu Danfodiyo University Sokoto, Journal of Business Studies Quarterly, Volume 5, Number 2.247-259. 